Illinois State University

ISU ReD: Research and eData

Theses and Dissertations

3-20-2017

\title{
The Use of Reappraisal during Expressive Writing and its Impact on Affect and Insight
}

Alleana Micaela Maglaque Fuentes

Illinois State University, amfuent@ilstu.edu

Follow this and additional works at: https://ir.library.illinoisstate.edu/etd

Part of the Clinical Psychology Commons, and the Counseling Psychology Commons

\section{Recommended Citation}

Fuentes, Alleana Micaela Maglaque, "The Use of Reappraisal during Expressive Writing and its Impact on Affect and Insight" (2017). Theses and Dissertations. 670.

https://ir.library.illinoisstate.edu/etd/670

This Thesis is brought to you for free and open access by ISU ReD: Research and eData. It has been accepted for inclusion in Theses and Dissertations by an authorized administrator of ISU ReD: Research and eData. For more information, please contact ISUReD@ilstu.edu. 


\title{
THE USE OF REAPPRAISAL DURING EXPRESSIVE WRITING AND ITS IMPACT ON AFFECT AND INSIGHT
}

\begin{abstract}
Alleana Micaela Maglaque Fuentes
66 Pages

This thesis looked into the role of reappraisal in expressive writing and its impact on affect and insight. The study looked into (1) differences in reappraisal between writing in the first person versus third person, (2) differences in one's perceived inclusion of the stressor in the self between the two groups, (3) changes produced in positive and negative affect, (4) outcomes on insight, and (5) the role of reappraisal as a mediator between expressive writing and its outcomes. 64 undergraduate students were asked to answer questionnaires and engage in a writing task. Results of the study are as follows: (1) writing in the third person does not lead to greater reappraisal; (2) through time, there was a decrease in the way people perceived the stressor to be included in the self; (3) through time, people decreased in positive affect and increased in negative affect; (4) writing in the third person did not lead to greater insight; and (5) reappraisal was not a mediator between expressive writing and its outcomes in affect and insight. Limitations, future directions, and implications of the study are explained in the paper.
\end{abstract}

KEYWORDS: Reappraisal, Expressive Writing, Affect, Insight 

AFFECT AND INSIGHT

ALLEANA MICAELA MAGLAQUE FUENTES

A Thesis Submitted in Partial Fulfillment of the Requirements for the Degree of

MASTER OF SCIENCE

Department of Psychology

ILLINOIS STATE UNIVERSITY 
(C) 2017 Alleana Micaela Maglaque Fuentes 


\section{THE USE OF REAPPRAISAL DURING EXPRESSIVE WRITING AND ITS IMPACT ON AFFECT AND INSIGHT}

ALLEANA MICAELA MAGLAQUE FUENTES

COMMITTEE MEMBERS:

Jeffrey Kahn, Chair

Scott Jordan

Daniel Lannin 


\section{ACKNOWLEDGMENTS}

I would like to thank all the people who have made the production of this thesis a meaningful experience. I would like to thank my thesis chair Dr. Jeffrey Kahn for the tremendous amount of support, wisdom, and motivation that he has provided throughout this process. I would also like to thank my thesis committee members Dr. Scott Jordan and Dr. Daniel Lannin for their insight in helping to develop this research. I also would like to thank Dr. Alexandra Ilie for her guidance and input in bettering this project.

I would like to thank two students whose time and effort would not have made the data collection for this thesis possible. Thank you Kyle Lawell and Benjamin Taour for your enthusiasm and efficiency in making this project work.

Finally, I dedicate this thesis to my parents Alex and Mary Ann Fuentes, and my sister Danielle Fuentes, whose love, prayers, and words of encouragement have driven me to accomplish more than I expected.

To God be all the glory!

A. M. M. F. 


\section{CONTENTS}

\section{Page}

ACKNOWLEDGMENTS

CONTENTS

TABLES

iv

FIGURES

CHAPTER

I. INTRODUCTION

II. REVIEW OF RELATED LITERATURE

Emotion Regulation

Reappraisal

Expressive Writing

Typical Writing Methods

Disadvantages of Expressive Writing 16

Expressive Writing and Its Benefits 16

Mechanisms Behind Expressive Writing $\quad 20$

Emotion Regulation and Expressive Writing $\quad 22$

Content and Function Words in Writing 25

Linguistic Inquiry and Word Count (LIWC) 26

$\begin{array}{ll}\text { First and Third Person Pronouns } & 27\end{array}$

$\begin{array}{ll}\text { The Present Study } & 29\end{array}$

$\begin{array}{ll}\text { III. METHOD } & 33\end{array}$

Participants $\quad 33$

$\begin{array}{ll}\text { Measures } & 33\end{array}$

Affect

Stress Questions $\quad 34$

Inclusion of the Stressor in the Self

Insight Questions $\quad 35$

Adapted Strategies Questionnaire $\quad 35$

$\begin{array}{ll}\text { LIWC } & 37\end{array}$ 
Procedure

$\begin{array}{ll}\text { IV. RESULTS } & 39\end{array}$

$\begin{array}{ll}\text { Stressor Questions } & 39\end{array}$

Manipulation Check $\quad 39$

First Person Descriptives and Correlations $\quad 40$

Third Person Descriptives and Correlations $\quad 42$

Correlations for Total Sample $\quad 43$

First Hypothesis: Reappraisal $\quad 44$

Second Hypothesis: Inclusion of the Stressor in the Self 45

Third Hypothesis: Affect $\quad 45$

Fourth Hypothesis: Insight $\quad 46$

Final Hypothesis: Mediational Model $\quad 46$

$\begin{array}{ll}\text { V. DISCUSSION } & 48\end{array}$

Limitations and Future Directions $\quad 53$

$\begin{array}{ll}\text { Implications of the Study } & 56\end{array}$

$\begin{array}{lr}\text { REFERENCES } & 59\end{array}$

$\begin{array}{ll}\text { APPENDIX A: INFORMED CONSENT } & 64\end{array}$

APPENDIX B: DEBRIEFING 66 


\section{TABLES}

Table

Page

1. Correlations, Means and Standard Deviations for the First Person Condition $(n=32)$

2. Correlations, Means and Standard Deviations for the Third Person Condition $(n=32)$ 42

3. Means, Standard Deviations, and Correlations for all Variables $(N=64)$ 


\section{FIGURES}

Figure

Page

1. Mediational Model $\quad 32$

2. Path Analysis Model Generated by the LISREL Software 


\section{CHAPTER I}

\section{INTRODUCTION}

Emotions are aspects of a person that can be helpful or harmful to themselves and the people around them, depending on how they are experienced and expressed. According to Gross and Jazaieri (2014), it was Aristotle who first talked about how emotions are beneficial when they are "expressed in the right way, last the right amount of time, arise in the right circumstances, and are about the right things" (p. 389). Emotions become harmful then when they are used with the wrong intensity, duration, frequency, or type for a particular situation, and when they create biases in how we think and behave -- the extent of which may even manifest in psychopathology (Gross \& Jazaieri, 2014). It is instances such as these, when emotions become maladaptive, wherein emotion regulation plays a crucial role in managing one's response to a situation (Gross, 2015).

There are several strategies that can be applied to regulate emotions effectively, and one of the most effective strategies has been found to be reappraisal (Gross, 2002). By focusing on the positive aspect of events and repairing negative moods through reinterpreting stressors, reappraisers manage their situations in a way that allows them to experience and express more positive emotions and fewer negative emotions (Gross \& John, 2003). Reappraisal tends to be marked with other positive outcomes including less depression, more self-esteem, better wellbeing, deeper relationships, and greater life satisfaction. Although this has been established, Gross (2015) stated that there remains a need to form and test interventions that are designed to shape emotion regulation processes towards helpful directions.

One such helpful direction might be towards expressive writing interventions. Expressive writing, a form of written emotional disclosure wherein one writes about negative experiences 
often marked by stress or trauma (Nazarian \& Smyth, 2013), has long been shown to produce advantages to a person's physical and psychological health (Frattaroli, 2006; Frisina, Borod, \& Lepore, 2004; Smyth, 1998). Medical benefits, positive behavioral changes, relationship advantages, as well as work and school performance improvements have also been shown to result from expressive writing (Baikie \& Wilhelm, 2005; Pennebaker \& Chung 2007; Slatcher \& Pennebaker, 2006). There is, however, a limited amount of evidence linking emotion regulation as a process that plays a role in expressive writing. Although emotion regulation has been proposed to be a mechanism that explains the health outcomes of expressive writing (Lepore, Greenberg, Bruno, \& Smyth, 2002), there remains a lack of research linking reappraisal to expressive writing.

One of the studies that would be closest to this is that of Campbell and Pennebaker (2003), which found that health improves for people who change their use of function words in their writing, specifically their pronoun use, from day to day. The more that people fluctuate in using first-person singular pronouns such as $I, m e$, and $m y$, and all other personal pronouns (we, you, she, they), the more health improvements were observed, due to the changes in orientation and personal attention in which the writers engaged. Given the changes in perspective brought about by changing pronoun use, it was of interest in this study to determine if reappraisal is, in fact, the strategy that is employed in bringing about positive expressive writing outcomes.

This present study specifically builds on this idea by looking into the role of reappraisal in expressive writing, in the context of writing in the first person or third person. In other words, how does reappraisal relate to the point of view of the writer? One of the goals in the study was to determine if there are differences in reappraisal when the writing is done in the first person versus the third person, and see whether reappraisal is indeed greater in the third-person writing 
condition. This is of interest, given the previous evidence that shows the benefit of shifting points of view by changing pronoun use (Campbell \& Pennebaker, 2003). Particularly, thirdperson pronoun use was linked to more adaptive coping and better physical health (Chung \& Pennebaker, 2007).

In addition, this study examined if there are differences in one's perceived inclusion of the stressor in the self between the first-person and third-person writing conditions. It was assumed that writing in the third person would reflect a lower inclusion of the stressor in the self between the person and the stressor compared to writing in the first person, given previous studies that show how third person writing allows for psychological displacement, or viewing one's situation with more distance and objectivity (Jin, 2005; Seih et al., 2008).

This study also looked into outcomes produced by writing in the first person versus the third person, wherein the impact of writing on immediate change in positive affect, immediate change in negative affect, and the development of post-writing insight were explored. It was predicted that the third-person writing condition would lead to the more favorable outcomes more positive affect, less negative affect, and greater insight - than the first-person writing condition, provided that doing so changes the way individuals think about and perceive their stressful situations.

Finally, the relationships among point of view in expressive writing, reappraisal, and changes in post-writing affect and insight were examined, and the role of reappraisal as a mediator was investigated. Given previous hypotheses on how reappraisal may be utilized more through the use of third-person rather than first-person pronouns, and how third-person pronoun use may lead to more favorable outcomes in post-writing affect and insight, it was predicted that positive relationships among the three variables are demonstrated, such that writing in the third 
person would lead to greater use of reappraisal, which then facilitates greater changes in postwriting affect and insight.

By investigating these outcomes, the study not only may add to the body of research on emotion regulation and expressive writing, but is may also serve benefits for individuals who experience a lot of stress, such as college students, who are often faced with multiple academic, social, and personal pressures (Brown, 1992). Since these stressors may make them more vulnerable to mood problems and disorders, finding a means to effectively deal with their stressful situations may be useful for this specific population. 


\section{CHAPTER II}

\section{REVIEW OF RELATED LITERATURE}

\section{Emotion Regulation}

Emotion regulation is the process by which individuals try to influence what emotions they have, when they surface, and how these are experienced (Gross, 1998). What distinguishes emotion regulation from other processes is the incorporation of a goal that would impact how a person's emotions are maintained or changed (Gross, Sheppes, \& Urry, 2011). The goals can be turned inward, wherein a person aims to regulate his/her own emotions, and this is referred to as intrinsic emotion regulation, whereas extrinsic emotion regulation is when a person's goal is to regulate someone else's emotions (Gross, 2015). Aside from goals, awareness and strategies also give rise to the adaptive nature of emotion regulation (Peña-Sarrionandia, Mikolajczak, \& Gross, 2015). Awareness of emotions and the contexts by which they exist allow for a decision to be made on whether or not to regulate the emotion and how to go about accomplishing this. On the other hand, strategies refer to the means by which the goal can be efficiently achieved.

Emotion regulation can lead to several advantages and disadvantages, depending on how a person engages in it (Gross, 2002). Individuals may also be unconsciously or consciously regulating their emotions, which may essentially involve increasing, maintaining, or decreasing negative and positive emotions. These changes in emotions can be measured in terms of different emotional aspects, including intensity, duration, and quality (Gross, 2015).

Gross (2002) constructed a process model of emotion regulation, which he divided into two parts. The antecedent-focused strategies consist of stages done before the full activation of the emotion response tendencies, which include situation selection, situation modification, attentional deployment, and cognitive change. Response-focused strategies are stages done after 
these emotion response tendencies have been created, which constitutes the response modulation stage.

The first stage of the process is situation selection, which refers to regulating emotions by approaching or avoiding particular people, places and things (Gross, 2002). Strategies involved in this stage are confrontation, wherein one decides to enter a situation despite potential negative emotions that may result from it, and avoidance, wherein a person escapes the situation as a whole (Gross, 2015). Situation selection is said to often have trade-offs between short- and longterm emotional benefits, and it varies between the two strategies. Confrontation, for instance, is most effective if the situation being approached has a high likelihood of bringing about longterm benefits in happiness and health. Avoidance, on the other hand, results in short-term benefits, but it may lead to long-term effects that are detrimental to a person's well-being. The next stage is situation modification, wherein an individual creates changes to the situation to modify its emotional impact (Gross, 2002). These can be done through several strategies, including direct situation modification or problem-focused coping, wherein actions that directly influence the situation are taken; help/support-seeking, where the help of others is sought to make the necessary changes to the situation; and conflict resolution, which includes a variety of steps to lessen the impact of a situation involving conflict (Gross, 2015). Of all these strategies, it is the direct situation modification or problem-focused coping strategy that is linked with better health outcomes, fewer psychological disorders, and increased well-being, since the actual source or root of the problem is addressed.

Following that stage is attentional deployment, which involves selecting what parts of a situation one desires to pay attention to (Gross, 2002). These can be done through distraction, wherein to shift attention away from the situation or the emotional aspects of it, a person can 
physically withdraw or internally refocus his/her attention (Gross, 2015). Rumination is another strategy for attentional deployment, wherein a person maintains focus on the negative thoughts and emotions associated with the situation. This leads to a longer and more intense experience of the negative emotions; thus, it is linked to the experience of depressive episodes, and is commonly seen in individuals suffering from mental health symptoms and disorders. Finally, mindfulness is another attentional deployment strategy, which engages individuals in the present moment as they focus on their internal and external world non-judgmentally. This strategy is associated with decreased stress, anxiety, and depression, as well as increased levels of happiness.

Cognitive change is the next stage, and it refers to modifying one's manner of thinking to change the way we think about the situation or our ability to handle it, thus affecting the way we feel (Gross, 2015). This stage involves sorting through the meanings assigned to a particular situation and selecting which of these personal meanings a person will associate with the event, which, in turn, impacts the experiential, behavioral, and physiological emotion response tendencies created as outcomes of the process (Gross, 2002). Cognitive change strategies include self-efficacy appraisal, wherein a person exudes confidence in his/her capabilities in handling the situation (Gross, 2015). Other strategies are threat appraisals, wherein an individual views a situation as beyond what s/he is able to manage, and pays attention to the losses that may come from the situation; and challenge appraisal, when a person experiences the same threatening situation, but focuses instead on the possible gains that can be achieved from it. Positive reappraisal involves putting things into perspective, and shifting towards optimism while looking for the silver lining in the situation. Lastly, for cognitive change, acceptance is the ideal strategy to use when situations are difficult to reappraise, and it is when a person simply comes to terms 
with the reality of the situation or his/her inability to handle it. Overall, cognitive change leads to a lot of positive benefits, such as lower levels of stress, pain, and negative emotion experience and expression, as well as increased immune system functioning.

The final stage in the process model of emotion regulation is response modulation, or the targeting of experiential, behavioral, and physiological aspects of the emotion response tendencies that have already been produced (Gross, 2002). Emotion sharing is a strategy wherein an individual describes an emotional event and verbally expresses emotions, which often leads to advantages in social relationships and connections with others (Gross, 2015). A strategy that leads to opposite effects, on the other hand, is verbal or physical aggression, wherein the focus of a person is to release physical tension accumulated in the body from the negative emotional situation, which then results in poor effects on health and relationships. Substance use is another commonly used response modulation strategy that leads to negative health outcomes, since a person attempts to manage the feelings and thoughts associated with the situation through taking alcohol or drugs. Lastly, expressive suppression, or the inhibition of expressing undesired emotions, also results in disadvantages to one's health and well-being, and is commonly used by people diagnosed with psychological disorders.

This basic process model of emotion regulation has recently been extended to include the concept of valuation, or the discrimination between what is good and what is bad for the self (Gross, 2015). As Gross (2015) puts it, the world is subject to multiple perceptions, and these perceptions are valued by individuals as positive or negative. Upon being valued as either negative or positive, these valuations give rise to actions that can modify the state of the world. Emotion regulation is said to be an occurrence resulting from a valuation system taking another valuation system as a target, evaluating it as positive or negative, and implementing actions that 
would create change in the first valuation system. The second-level valuation system can impact the first level in different ways, which coincide with the process model of emotion regulation. Situation selection and situation modification involve changing the external world individuals are exposed to, while attentional deployment is the change in the perceptions of the world. Cognitive change is the shift in ways by which one represents the world in thoughts, and response modulation is the alteration of actions prompted by emotions experienced.

Gross (2015) identifies three valuation stages; namely, the identification stage, selection stage, and implementation stage. The identification stage begins with a detection of the emotion, then an evaluation of whether or not to regulate it, and ends with the determination of which choice is to be made. The sub-steps involved in this stage are perception, where the detection of the emotion occurs; valuation, where the positive or negative value attached to the emotion is determined; and action, where the goal of regulating the emotion, if this is chosen, is activated.

The selection stage focuses on selecting what specific emotion regulation strategy is appropriate for the situation (Gross, 2015). The perception sub-step is responsible for representing the potential emotion regulation strategies that may be used, while the valuation sub-step considers the context, available resources, and nature of the emotion, in order to determine what strategy would be the most effective to use. For instance, when the intensity of the emotion is low, people tend to turn to reappraisal rather than distraction, but the opposite is preferred when the emotional intensity is high. The action sub-step then activates the goal to use a specific strategy.

The final stage, the implementation stage, is where implementation of the chosen strategy for the situation takes place (Gross, 2015). Instead of simply using the general strategy, specific tactics are initiated to suit the situation experienced. The perceptual sub-step begins with the 
representation of the world and the different ways to implement a strategy. The tactics within a strategy are evaluated in the valuation sub-step, wherein the ones that show most potential for effectiveness are applied. Lastly, the action sub-step refers to the output of the actual implementation of the emotion regulation strategy.

When outcomes across the three stages of identification, selection, and implementation are achieved, this process of emotion regulation is maintained (Gross, 2015). Now that we have an overview of the process of emotion regulation, we shall turn to reappraisal, one of the strategies used in the cognitive change stage, which was the focus of this present study.

\section{Reappraisal}

Reappraisal is a strategy of cognitive change that focuses on the meanings and selfrelevance of a potentially emotion-eliciting situation (Gross, 2015). Although reappraisal can be used to increase or decrease both positive and negative emotions, it is generally applied to negative emotion-eliciting situations where the intensity of the emotion is desired to be decreased. Some general outcomes of reappraisal that have been found include enhanced exam performance, improved memory, decreased sympathetic nervous system responses, lessened activation in emotion-generating brain regions such as the amygdala and ventral striatum, and reduced levels of negative emotion experience (Gross, 2015).

In clinical studies, reappraisal and suppression strategies are frequently compared to each other, as they are often used to down-regulate emotions. Reappraisal, a type of cognitive change, comes early in the emotion-generative process and is antecedent-focused. In contrast, suppression, a type of response modulation, comes later in the process and is response-focused (Gross, 2002). Whereas suppression prevents the display of feelings, reappraisal involves modifying the perception towards a situation to decrease its emotional impact. In terms of 
effects, behavioral expression is decreased in suppression; however, the emotional experience remains unchanged. The physiological response actually increases, and memory is even damaged. Reappraisal does not impact memory, and is able to decrease both emotional experience and behavioral expression.

Looking further into the consequences for each, reappraisal and suppression influence the affective, cognitive and social aspects of an individual (Gross, 2002). Whereas reappraisal influences the entirety of the emotional response, specifically decreasing experiential, behavioral and physiological responses; suppression varies in its effects and is shown to increase physiological response and decrease expressive behavior, but not the emotional experience. In general, people who have greater tendencies to suppress than others feel more negative emotions, whereas individuals who tend to score higher on reappraisal than others achieve not only greater positive emotion experience and expression but also lessened negative emotion experience and expression.

Cognitively, suppression requires continuous activity, given the constant self-monitoring and self-corrective action a person engages in while experiencing an emotional situation. With this high amount of cognitive activity, fewer resources are available for the processing and remembering of events; thus, memory is not kept intact (Gross, 2002). As for reappraisal, which is utilized earlier in the emotion regulation process, continuous self-regulation is not required during the emotional event, so resources are left available for processing and remembering the situation, thus keeping memory intact.

Finally, for the social aspect, suppression often leads to disadvantages in social relationships, since the decrease in emotional expression can provide little or inaccurate information to others about what the individual may be feeling or going through (Gross, 2002). 
Individuals who suppress more than others also tend to put a lot of energy into monitoring their own vocal and facial expressions, so they may find it taxing to appropriately and effectively respond to the people they are interacting with, and this may negatively influence the quality of social communications. On the other hand, although reappraisal does not necessarily have direct links to improving social relationships (since it decreases negative emotion experience and expression, increases positive emotion experience and expression, and does not demand too much cognitive activity), positive social consequences are predicted for the social behavior of people that reappraise more than others.

In another series of studies that looked into individual differences between the two emotion regulation processes, Gross and John (2003) looked at suppression and reappraisal alongside several variables. When comparing group differences, reappraisal showed no differences between men and women and no differences among ethnic groups. Suppression, however, showed differences in gender and ethnicity, such that men and minority groups scored higher on suppression. Men were said to score higher on suppression due to Western norms that expressing emotions tend to be seen as unmanly, whereas minority groups suppressed more as a way to avoid upsetting the majority group that is often perceived as of higher status (Brody, 2000; Keltner, Gruenfeld, \& Anderson, 2003).

The second part of Gross and John's (2003) study looked into the constructs of emotion regulation success, inauthenticity, coping, and mood regulation, among others. Both reappraisal and suppression were correlated positively with the perception that one's emotion regulation efforts are successful. This makes senses since individuals tend to choose the strategies that will help them achieve their emotion regulation goals. When it comes to inauthenticity, suppression was positively related to it, but reappraisal was not. This perception of inauthenticity for 
suppressors may be due to the portrayal of a different image of themselves to other people. In terms of coping, people who score high on reappraisal tend to cope through interpretation, whereas those who score high on suppression tend to cope through venting. For individuals who score high on reappraisal, they specifically try to maintain optimism in the face of stressful situations. Meanwhile, individuals who score high on suppression are more likely to express their upset feelings towards their negative experience. The measures for reappraisal and suppression were measured for convergent validity with the Trait Meta-Mood scales (Salovey, Mayer, Golman, Turvey, \& Palfai, 1995) -- three scales that measure Repair (optimism and application of distraction to improve negative mood), Attention (awareness and positive valuation of feelings), and Clarity (clarity and comfort with emotions). Reappraisal was specifically found to be associated with the Repair scale that measures mood repair, wherein individuals who reappraise focus on working on their negative moods by being optimistic or using distraction. Thus, it is no surprise that the efficacy of negative mood regulated showed a positive relationship to reappraisal and a negative relationship to suppression.

The Big Five personality scales were also correlated with the emotion regulation measures, and reappraisal was found to be negatively related to neuroticism, whereas suppression was negatively related to extraversion (Gross \& John, 2003). When looking at ego control, cognitive ability and social desirability, both reappraisal and suppression showed no relationship to the aforementioned constructs.

The third part of the Gross and John (2003) study replicated earlier findings on experience and expression of affect by Gross (2002), wherein individuals who score highly on suppression were found to experience and express less positive affect, and experience more negative affect. Individuals with high reappraisal scores, through their reinterpretation of 
stressful events and repair of negative moods, experience and express more positive emotions and less negative emotions.

The fourth part of the study looked into peer reports to see the role of reappraisal and suppression in social relationships (Gross \& John, 2003). Reappraisal is positively related to sharing both positive and negative emotions, which allows for closer relationships with people and higher likability ratings from peers. Reappraisal is not related to measures of attachment avoidance or measures of social support, which implies that people who score high on reappraisal are no more likely to seek out attachments and social support than people who reappraise less. People who score high on suppression are less likely to share both positive and negative emotions, and are also seen to engage in more avoidance and have less social support.

Finally, the last part of the study looked into measures of well-being (Gross \& John, 2003). Suppression was linked with poorer levels of well-being marked by low positive relations with others, low self-esteem, low satisfaction towards life, and a high number of depressive symptoms. People with high reappraisal scores, on the other hand, experience better well-being, and show less depression, more self-esteem and greater life satisfaction. Given all these differences between the two emotion regulation processes, reappraisal is often seen as the more effective strategy compared to suppression (Gross, 2002).

Given this information, we can see that emotion regulation, and the specific strategies of reappraisal and suppression, have been well-studied. However, as mentioned earlier, there remains a need to form and test interventions that are designed to shape emotion regulation processes towards helpful directions (Gross, 2015). One such direction may be in the form of expressive writing interventions. 


\section{Expressive Writing}

Writing about negative experiences, often marked by trauma or stress, defines the concept of expressive writing (Nazarian \& Smyth, 2013). Also called written emotional disclosure, this intervention allows individuals to not only explore their emotions and thoughts, but also express and process them in a manner that is structured and kept confidential (Baikie \&Wilhelm, 2005; Nazarian \& Smyth, 2013).

The first experimental study on expressive writing was conducted in 1986, by psychologist James Pennebaker, along with Sandra Beall, wherein they asked college students to either write about superficial topics or traumatic experiences for 15 minutes a day across 4 days (Pennebaker \& Beall, 1986; Pennebaker, 2010). The promising results, which found that those who wrote about trauma had fewer visits to the student health center for illness compared to those who wrote about superficial topics, catapulted numerous studies on expressive writing over the years.

\section{Typical Writing Methods}

The method of expressive writing typically involves writing about traumatic or upsetting experiences, the thoughts and feelings that accompany it, as well as other aspects of the individual's life that may be associated with the event (Pennebaker, 2010). Depending on the nature of the study, specific issues appropriate to the topic are also sometimes covered, including specific diagnosed diseases such as cancer or AIDS, and significant life changes like divorce or a death in the family. The writing is ideally done at least three times, each in no less than 15 minutes. The three times by which the task is done can be separated by 10 minutes or even one week, although 1-2 day intervals are preferred. Individuals are encouraged to write about the distress continuously, without the need to abide by strict grammatical and spelling rules. In 
accomplishing this writing task, it is crucial that individuals are given the liberty to write about anything that is troubling them.

\section{Disadvantages of Expressive Writing}

Given that the writing task is done within a short period of time, and since the process involves unearthing upsetting experiences with minimal space for processing, disclosing such information often leads to negative moods and even physical symptoms (Pennebaker, KiecoltGlaser, \& Glaser, 1988). The short-term effects for individuals who engage in expressive writing are then said to often be negative (Baikie \&Wilhelm, 2005). In addition, the method of expressive writing is personal and kept anonymous, and this prevents it from being subject to objective outside opinions, and support from others, for which people who have just opened up about their troubling thoughts and feelings can benefit (Pennebaker, Kiecolt-Glaser, \& Glaser,

1988). Lastly, the individuals who engage in expressive writing are also left without information on how to cope with the effects of the negative event they have experienced, which may lead to distress and leave the problematic situation to remain unresolved.

\section{Expressive Writing and Its Benefits}

As mentioned, immediate outcomes that arise from expressive writing include increased distress, negative mood and physical symptoms, and decreased positive mood (Baikie \& Wilhelm, 2005). These results seem less than favorable, but they are understandable, given the distressing nature of reliving a painful experience and writing about the specific details included in the incident. In the long run, however, a plethora of health benefits are observed in individuals that engage in expressive writing.

These various benefits of expressive writing interventions have been documented, and Pennebaker and Chung (2007) outline four major meta-analyses that have looked into the effects 
of engaging in expressive writing. Each of the meta-analyses have distinct populations and types of studies reviewed, with the first focusing on healthy participants (Smyth, 1998), the second involving clinical populations (Frisina, Borod \& Lepore, 2004), the third solely using randomized controlled trials on expressive writing (Harris, 2006), and the fourth, deemed as the largest meta-analysis so far, using all randomized expressive writing experiments (Frattaroli, 2006).

Looking at the results of each meta-analysis individually, it is generally observed that expressive writing does produce positive outcomes in a person's health and functioning. Smyth (1998) concluded that written emotional expression creates significant health benefits in healthy participants $(d=.47)$, and significant effect sizes were obtained in different aspects of a person's well-being, including physiological $(d=.68)$, psychological $(d=.66)$, health $(d=.42)$, and general functioning outcomes $(d=.33)$.

A meta-analysis by Frisina, Borod, and Lepore (2004) was conducted in a similar way as Smyth's (1998), although instead of healthy participants, they focused on clinical populations, or individuals physically and/or psychiatrically ill. Expressive writing was said to significantly improve health $(d=.19, p<.05)$, with greater effects on physical $(d=.21, p=.01)$ than psychological $(d=.07, p=.17)$ health outcomes. An interesting explanation provided for the greater effectiveness of expressive writing on physical health over psychological health is that cognition may be disrupted in people with psychological or psychiatric illnesses, which limits the ability of individuals to engage in a task that requires thought processing. This may, for instance, be ineffective for people with severe depression, suicidal ideation, or PTSD. However, expressive writing still holds clinical relevance for people suffering from mood disorders, such as depression, as well as medical relevance for individuals suffering from different types of 
diseases - from low-risk diseases such as asthma and arthritis to diseases with high mortality rates such as cancer. Its ability to place minimal burden on the individual's condition and finances are additional benefits.

Focusing on randomized controlled trials, Harris (2006) concluded that expressive writing decreases health-care utilization in healthy individuals. Health-care utilization generally refers to one's use of the health-care system, often measured in number of visits to the doctor. The same cannot be said though for people with existing medical conditions such as fibromyalgia, cancer, cystic fibrosis, and irritable bowel syndrome, or psychological stresses and diagnoses including trauma, suicidal ideation, somatic symptoms, and bereavement. In these conditions, no significant decreases in their health care utilization were obtained. Although this is the case, Harris (2006) saw this as a positive outcome, given the reality that individuals with relapsing chronic illnesses need a large and frequent number of visits to their physicians, which increases health care utilization, and, in turn, leads to better health outcomes.

To include numerous studies that were not considered in previous meta-analyses, Frattaroli (2006) conducted a meta-analysis on 146 randomized studies on experimental disclosure and obtained a positive and significant effect size of $r=.075$, suggesting the effectiveness of expressive writing on psychological health, physical health, and overall functioning. Given its random effects approach, Frattaroli (2006) says the existence of the effects may also be evident in similar studies not included in her present meta-analysis. Beyond providing support for the positive effects of expressive writing on health, the study was also able to identify several moderators that allowed for larger effect sizes. These studies involved individuals with a history of trauma or stress, participants with only physical health concerns, and people who wrote about more recent events, among others. 
From these meta-analyses, we can summarize that expressive writing brings about positive outcomes. As for the specific aspects of a person's health and well-being, Pennebaker and Chung (2007) list the following as physiological effects brought about by engaging in expressive writing interventions: drops in physician visits, immune function effects including influences on t-helper cell growth and antibody responses, improved autonomic nervous system activity, lower skin conductance levels, as well as decreased blood pressure and heart rate. Greater physiological activation marked by higher cortisol levels was also observed at the initial session, and these levels later decreased in future sessions, which was overall said to be beneficial for a person's psychological health. In addition, medical populations found to benefit the most from expressive writing include people with asthma, cancer, HIV infections, cystic fibrosis, and sleep problems (Baikie \& Wilhelm, 2005).

In addition, grade improvements, new jobs, better attendance at work, long-term improvements in mood and well-being, and a general reduction in distress were found as some results of participating in the written emotional disclosure exercises (Pennebaker \& Chung, 2007). In terms of relationships between people, expressive writing has also been found to be a tool that allows for opportunities to reflect, which in turn, increases emotional expressiveness with others (Slatcher \& Pennebaker, 2006).

The effects of expressive writing on psychological conditions garnered mixed results, and the greatest benefits were observed for those with a trauma history (Baikie \& Wilhelm, 2005). Expressive writing was said to bring about improvements in physical health, PTSD symptomatology, and other aspects of psychological health. Although limited, benefits were also found in the psychological well-being of several populations, including male psychiatric prison inmates, victims of natural disasters, and individuals who experienced a recent relationship 
breakup. Beneficial outcomes were also seen from expressive writing in females that wrote about body image, children of alcoholics, caregivers of children with chronic illness, students screened for suicidality, and individuals who have experienced a bereavement; however, these effects were not significant. Generally, expressive writing can be said to create more positive benefits when the trauma and accompanying symptoms are clinically more severe.

Overall, the link between expressive writing and its overall positive benefits to a person's health has been established. However, the same cannot be said for the reasons why this is so.

\section{Mechanisms Behind Expressive Writing}

Numerous mechanisms behind expressive writing have been offered, and each one shows promise that it can explain why expressive writing works (Pennebaker \& Chung, 2011). One of these mechanisms is based on the idea that when a person inhibits thoughts and emotions associated with traumatic experiences, such an act negatively influences that individual's health (Pennebaker \& Chung, 2011). This is because holding back thoughts, emotions, or behaviors is associated with low physiological work, which is not ideal when faced with stressful situations, wherein the body needs to be activated in a way that allows us to respond to the stress (Sapolsky, 2004). When the person is then provided with the opportunity to talk or write about these previously inhibited events, health improvements abound.

Another mechanism is based on the concept of emotions, wherein expressive writing is found to bring about health changes when individuals are able to go outside the facts and actually engage in emotional experiences in an expressive writing activity (Pennebaker \& Chung, 2011). Beyond experiencing emotions, having the ability to express emotions in a cathartic fashion when individuals translate their feelings into words specifically leads to these gains in health. 
With expressive writing, emotional experiences are given verbal labels, which allows the individuals to conceptually process the event by giving meaning to the emotions involved in it (Pennebaker \& Chung, 2011). This leads to the event being eventually resolved or forgotten, which can relieve the person from the dysfunctional effects the experience has brought on one's health. Looking specifically at the labels given to emotions, differentiations between the use of negative and positive words is said to contribute to health status (Pennebaker \& Chung, 2011). Higher use of positive emotion words, such as happy or laugh, is associated with improved health, whereas negative emotion word use, such as sad or angry, has a curvilinear relationship with health change. This curvilinear relationship can be best exemplified in the finding that the largest drop in physician visits was found in people who displayed a moderate use of negative emotion words, while those on the extreme ends--using either a very low or high rate of negative emotions words--showed a greater probability of remaining sick after writing.

Expressive writing also involves storytelling in a manner that is structured and integrated, and such coherence in written stories proves advantageous for a person's well-being (Pennebaker \& Chung, 2011). A specific manner of coherently describing an experience is through cognitively organizing the event, which manifests in the use of insight and causal words. Insight words, such as understand or realize, demonstrate an ability to know and remember the event, whereas causal words, such as because and reason, demonstrate an understanding of the experience in a wider perspective. Insight and causal words, coupled with positive emotion words, altogether represent a positive reappraisal of the event, which allows one's mindset and thoughts to expand. This cognitive organization is linked not only with better health, but also with a decreased intrusion of the negative experiences associated with the traumatic event. 
Writing about the emotional events that one has gone through also leads that person to talk more about it (Pennebaker \& Chung, 2011). Since circumstances that were once hidden have been expressed through writing, people get more encouraged to speak to others about them with openness, which in turn positively influences how they relate to others in social environments.

People who are in the midst of a crisis or have recently experienced challenging situations rarely get the chance to examine their lives (Pennebaker \& Chung, 2011). By engaging in expressive writing, these people are provided the time and opportunity to take a step back from their environment, in order to reflect and process the emotional experiences they have had or are going through.

Finally, expressive writing facilitates changes in perspective-taking for the writer (Pennebaker \& Chung, 2011). Health improvements are seen in people who are able to oscillate in their use of first-person singular pronouns such as $I, m e$, and $m y$, and all other personal pronouns including we, you, and they (Campbell \& Pennebaker, 2003). Such switching and shifting in pronoun use can impact health, because individuals are able to change their orientation and attention.

\section{Emotion Regulation and Expressive Writing}

Several mechanisms for why expressive writing works have been offered, and some of the strongest evidence points to cognitive-processing theories. According to cognitive-processing theories, expressive writing not only allows for a process of letting go as an individual writes about her or his traumatic and stressful experiences, but people are also able to make sense of what they have been through, gain insight into the situations that have transpired, and organize and integrate the event into one's self-schema (Frattaroli, 2006). Despite this strong argument from cognitive-processing theories, Frattaroli (2006), in her meta-analysis, stated that for studies 
that could not be explained by cognitive processing, it was the emotion-regulation model that was able to explain the advantages of expressive writing.

As a whole, the process of expressive writing, especially when it follows the format of writing multiple times, can allow people to feel a sense of mastery as they gain a perspective of themselves as capable of expressing and managing their emotions (Frattaroli, 2006). Seeing this capability strengthens the confidence of individuals in their ability for emotion regulation, which, in turn, allows them to view challenges as more controllable, and, in the long-run, find themselves experiencing fewer negative emotions and more positive well-being outcomes. Another way of looking at how emotion regulation may lead to benefits in expressive writing is seeing how specific emotion regulation processes can result in a more balanced emotional life (Lepore, Greenberg, Bruno, \& Smyth, 2002). In between the act of expressive writing and the positive physical and mental health outcomes it leads to are the emotion-regulatory processes of attention, habituation and cognitive restructuring.

Expressive writing facilitates the process of attention (Lepore, Greenberg, Bruno, \& Smyth, 2002). By writing, people can attend to stress - its various aspects, sources, and outcomes, which allows for further facilitation of other emotion-regulation processes. It lends people to observing the situation and the way one responds subjectively, physiologically, and behaviorally to the event. Writing allows an individual to direct their attention to both the positive and negative aspects of stressors. When people pay attention to the negative aspects of the stressful situation or event, they refrain from the maladaptive behavior of avoiding painful feelings and thoughts. Instead, they are encouraged to express negative emotions, which lends itself to advantages, given that people are free from the tiresome act of controlling the expression of emotions. On the other hand, when people direct their attention towards the positive things 
brought about by their current or past stressors, positive emotions are tapped into, which enhance mood and health, as these shield against the negative aspects of their challenging situation. As a whole, directing attention to both the negative and positive aspects of a stressor is said to be beneficial. Clinically, it is the people who tend to over-regulate their emotions who may find it advantageous to pay attention to their negative feelings and thoughts, and those who tend to under-regulate their emotions who may find it beneficial to shift their attention away from the negative, and towards the positive aspects of the event.

Aside from attention, habituation also mediates between expressive writing and its positive outcomes (Lepore, Greenberg, Bruno, \& Smyth, 2002). Going back to the ideal method of writing for about three times, expressive writing can lead to lessened intensity in stress responses with repeated exposure to the painful aspects of the event. Since a person encounters the stressful stimuli more than once through writing about it, eventually those stressful stimuli do not have the same negative hold on a person, allowing them to experience less stress when remembering it. Expressive writing allows an individual to engage in the process of initially experiencing strong emotions, which gradually fades as the writing progresses.

Lastly, cognitive restructuring or cognitive change in expressive writing also takes place, wherein as people write, they can change their thoughts regarding the stressful situation they are describing (Lepore, Greenberg, Bruno, \& Smyth, 2002). Expressive writing not only allows them to change how they view the situation but also change the perspective on their responses to it, both of which lend to how effectively they regulate their emotions. Specifically, the reappraisal strategy can allow individuals to reevaluate what an event means and consider other meanings, thus changing the experience of the person with that event (Wang, et al, 2015). As they actively reappraise while engaging in expressive writing, this may challenge them to rethink some 
attitudes and beliefs they have, especially dysfunctional ones, which, in turn, influences how they emotionally respond in the long-run. In addition, reappraising in writing also influences the individual by improving their work behavior and relationships, decreasing illness, and increasing positive health outcomes (Alparone, Pagliaro, \& Rizzo, 2015).

Expressive writing in general allows people to be more in touch with themselves, which makes them more accepting of their emotions (Lepore, Greenberg, Bruno, \& Smyth, 2002). They are not only stripped of the need to present themselves in a certain way as they write, but they are also able to acknowledge and express their feelings, which implies that doing so is acceptable, and that their emotions are valid and can actually serve advantages for them. Especially for those suffering from mental disorders, which often are marked by abnormalities in the ability to regulate emotions, expressive writing allows for individuals to adjust to their traumatic and stressful events through facilitating these emotion regulation mechanisms.

\section{Content and Function Words in Writing}

With the emerging interest in expressive writing, one of the specific aspects that has been looked into by researchers such as Pennebaker (2011) are the words that texts comprise. Pennebaker distinguishes between content words and function words, wherein content wordswhich include nouns, verbs, adjectives and adverbs—are defined as linguistic elements that represent labels for acts or things whose meaning is understood by people sharing the same culture. Function or style words, on the other hand, include pronouns, articles, prepositions, auxiliary verbs, negations, conjunctions, and quantifiers, all of which are used to connect content words together. Whereas content words are used to express ideas to other people, function words, which are also called junk words, do not convey meaning to anyone. Instead, they contain in them the underlying cognitions within individuals that carry psychological meanings and set 
the stage for interpersonal interactions (Chung \& Pennebaker, 2007). In essence, content words talk about what one says and function words demonstrate how one says it (Pennebaker \& Chung, 2011).

Function words are further described as being short, frequently used, and difficult to spot (Pennebaker, 2011). These words are also said to be processed differently in the brain compared to content words, wherein the Broca's area is associated with function words and the Wernicke's area is more closely linked to content words. Since the Broca's area in the frontal lobe of the brain is responsible for several roles concerning social skills such as expressing and controlling emotions, reading facial expressions, and establishing relationships, the social aspect of function words is attributed to this.

Function words contain a social aspect, such that people who use more function words in a conversation would require higher levels of social knowledge and skills. This is because functions words are tied to the relationship between the speaker and listener, aside from denoting information about the speaker's location in time and space. In general, function words contain the ability to reflect the meanings people attribute to the events and objects they encounter and experience, which provide avenues to make linguistic shifts as each one engages in conversations.

\section{Linguistic Inquiry and Word Count (LIWC)}

Since function words are slowly being recognized more and more by researchers as essential elements that reveal how a person is thinking and speaking, Pennebaker and his team of researchers developed a software called the Linguistic Inquiry and Word Count (LIWC). This program was initially created to understand the language people used in writing about emotional experiences and life events (Chung \& Pennebaker, 2007). Since the 1980s, when expressive 
writing studies began to be conducted, the positive benefits towards physical health improvements were detected from a simple exercise of having people write about traumatic experiences for 15 to 30 minutes per day, for 3 to 4 days. LIWC then opened up a way so that the specific word types that were correlated with the positive health changes could be identified.

LIWC was developed by having groups of individuals serving as judges evaluate the association of about 2,000 words with several categories (Pennebaker \& Chung, 2011). The resulting categories were then classified into categories such as negative-emotion words, positive-emotion words, causal words, and insight words. Currently, LIWC functions in computing the percentage of total words that these and other linguistic categories, such as function and content words, represent. As a program, LIWC is notable for its ability to compare texts, on top of producing fast and consistent outcomes (Pennebaker, 2011). However, the tool is not perfect, since it is unable to detect features of language that may require actual human interaction, such as irony, sarcasm, and humor. In general, although it does fail to capture the context of language as a whole, it is a highly reliable tool that can provide insights about people's emotional states by simply counting the words used to represent how they think and feel.

\section{First and Third Person Pronouns}

The LIWC has been applied to analyze function-word use, especially the use of pronouns, and several differences were found in various age groups, gender, and status (Kacewicz, Pennebaker, Davis, Jeon, \& Graesser, 2013; Pennebaker, 2011; Pennebaker \& Stone, 2003; Pennebaker, Groom, Loew, \& Dabbs, 2004; Newman, Groom, Handelman, \& Pennebaker, 2008). There is minimal research focusing specifically on first- versus third-person pronoun use, but, in general, first-person pronouns have been found to be associated with more attention to the 
self. They are often used in greater extent by populations such as depressed college students, suicidal poets, honest people, individuals with higher blood pressure, persons of lower status, females, and younger generations (Chung \& Pennebaker, 2007). Third-person pronouns are specifically linked to increased reference to other people, and they are often used by individuals with lower testosterone levels. Between the two types of pronouns, it has been observed that higher usage of third-person pronouns is associated with better physical health, since it signifies more adaptive coping.

In a study that asked participants to write in a diary by initially using first-person pronouns, writing again using second-person pronouns, and finally writing with third-person pronouns, changes in perspective were found as individuals shifted in psychological distance from one's experiences to an objective evaluation of the event - a process Jin (2005) coined as psychological displacement. Furthering this study, Seih, Lin, Huang, Peng, and Huang (2008) demonstrated that highly anxious people benefited the most from effects of this form of writing. The authors specifically identified the first-person pronoun phase as facilitating emotional disclosure, the second-person pronoun phase as allowing a self-supportive dialogue with oneself, and the third-person pronoun phase as actualizing a personal emotional experience from an objective and distant position.

The present study looked into the use of first- and third-person pronouns. This is of interest because, even though pronouns are parts of statements that are often not recognized and even ignored, they possess the capacity to reveal many things about how people think (Campbell $\&$ Pennebaker, 2003). Further, despite being small and inconspicuous elements in a person's writing, pronouns serve as markers for psychological and physical health, which serves several benefits to one's well-being. 


\section{The Present Study}

Tying together the concepts of emotion regulation, expressive writing, words, and pronouns, this current study examined the role of reappraisal in expressive writing. It also investigated the role of inclusion of the stressor in the self and how these vary in the use of either first person or third person pronouns. In addition, it tested the impact of writing in the first person or third person on an individual's post-writing affect and insight. It also explored mediating effects of reappraisal in first- and third-person pronoun use on corresponding outcomes on post-writing affect and insight.

The first goal of this study was to find out if there are differences in reappraisal when individuals use first-person pronouns versus third-person pronouns. It was hypothesized that using third-person pronouns would facilitate a greater use of reappraisal. This assumption was based on the very definition of reappraisal, which implies a change in thinking about one's stressful situation and a shift in perspective on the meanings attributed to it (Lepore, Greenberg, Bruno, \& Smyth, 2002; Wang, et al., 2015). It was predicted that by writing in the third person, instead of the usual first-person perspective in expressive writing, individuals can shift their perspective away from the self and take on an outsider's point of view towards their stressful situation, which would then allow for changes in thinking about their experience. Specifically, threatening stimuli may be thought of as less personally threatening, and people may be able to more objectively reflect upon their current concerns (Jin, 2005; Seih et al., 2008).

Closely tied to this, the second goal of the study was to compare differences in perceived inclusion of the stressor in the self between individuals that wrote in the first person versus the third person. Perceived inclusion of the stressor in the self refers to how closely people view their stressor as a part of themselves. Following the previous hypothesis, it was assumed that the 
third person condition would reflect lower inclusion of the stressor in the self, whereas the first person condition would reflect a higher inclusion of the stressor in the self. This hypothesis stems from previous studies that show how third person writing creates psychological displacement, or a change in perspective, wherein one's situation is viewed with more distance and objectivity (Jin, 2005; Seih et al., 2008).

The third goal of the study was to investigate the impact of writing in the first person and third person on an individual's post-writing affect, and to specifically determine which condition leads to more favorable affect. Favorable post-writing affect is operationalized as a decrease in negative affect and an increase in positive affect. It was hypothesized that writing in the third person will result in more favorable post-writing affect than writing in the first person. Previous literature has shown evidence of short-term effects of expressive writing in terms of increasing negative mood and decreasing positive mood (Baikie \& Wilhelm, 2005). This is because only a short time is allotted for disclosing about upsetting experiences (Pennebaker, Kiecolt-Glaser, \& Glaser, 1988). Since expressive writing in these past studies was done from a first-person point of view, it was expected that writing in the first person would echo these less favorable effects on post-writing affect, whereas writing in the third person may lead to a more favorable post-writing affect, similar to results in studies by Jin (2005) and Seih et al. (2008). This more favorable postwriting affect was expected to arise from the distance created by shifting perspectives - in other words, greater use of reappraisal - that third person-writing was expected to facilitate (Jin, 2005; Lepore, Greenberg, Bruno, \& Smyth, 2002; Pennebaker \& Chung, 2011; Seih et al., 2008; Wang, et al., 2015).

The fourth goal of the study was to identify whether post-writing insight on one's stressful situation differed between the first-person and third-person conditions. Post-writing 
insight referred to an individual's self-reported gained understanding of the stressful event experienced. It was expected that writing in the third person would result in greater post-writing insight compared to writing in the first person. Again, this assumption was based on reappraisal as the mechanism leading to this outcome, wherein it was predicted that taking a step back away from the situation and putting one's self in the shoes of an outsider may allow for far greater insights when viewing one's stressful experience (Jin, 2005; Lepore, Greenberg, Bruno, \& Smyth, 2002; Pennebaker \& Chung, 2011; Seih et al., 2008; Wang, et al., 2015).

Lastly, the final goal of the study examined whether reappraisal mediates the relations between expressive writing and its outcomes in post-writing affect and insight. It was hypothesized that reappraisal does mediate the effects in post-writing affect and insight of expressive writing. Specifically, positive relationships were predicted between the expressive writing condition and reappraisal, and between greater reappraisal and outcomes for post-writing affect and insight. These predicted positive relationships specifically entail that writing in the third person leads to more favorable post-writing affect, in the form of more positive affect and less negative affect, in addition to greater post-writing insight. These relationships also imply that writing in the third person facilitates greater use of reappraisal and that this greater use of reappraisal would facilitate greater changes in post-writing affect and insight, as illustrated in Figure 1.

By looking at the potential impact of reappraisal in expressive writing through the use of third-person pronouns, this study adds to the limited body of research involving reappraising through pronoun use in expressive writing. In addition, given the potential for favorable outcomes in post-writing affect and insight that writing in the third person provides, this study can also contribute to the means by which populations such as college students manage and deal 
with stressful situations, especially considering the vulnerabilities of these individuals to stress and mood problems (Brown, 1992).

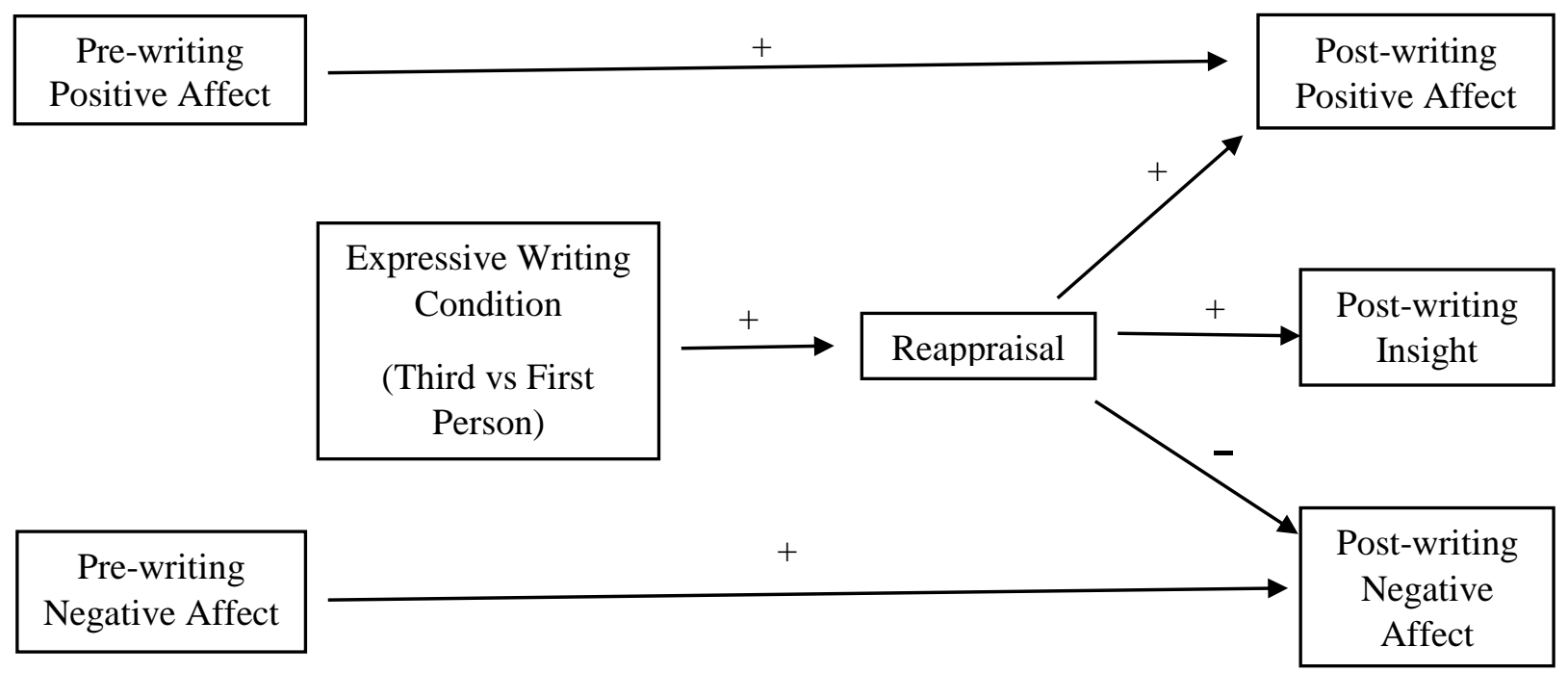

Figure 1. Mediational model. This model indicates the hypothesized relationships among expressive writing, reappraisal, pre-writing and post-writing positive and negative affect, and post-writing insight. The model shows the predicted direction of these relationships. 


\section{CHAPTER III}

\section{METHOD}

\section{Participants}

The current study recruited 64 undergraduate students from Illinois State University. As mentioned, this population is prone to several sources of stress and vulnerabilities to mood problems and disorders (Brown, 1992); thus, there is a need to measure the effectiveness of third-person expressive writing with these individuals. The sample size chosen $(N=64)$ was based on the medium effect size that a previous meta-analysis showed for expressive writing in healthy participants (Smyth, 1998). The ages of participants ranged from 18 to $36(M=19.90$, $S D=2.40)$. As for biological sex, the majority were female $(81 \%)$. Most of the students identified as Caucasian/White (70\%), which is quite representative of the student population in the university. Other ethnicities were also represented in the study, including African American (14\%), Hispanic/Latino (9\%), and Asian/Pacific Islander (6\%).

\section{Measures}

\section{Affect}

Positive and negative affect was measured with the Positive and Negative Affect Schedule - Expanded Form (PANAS-X; Watson \& Clark, 1999). The PANAS-X contains various adjectives identifying positive and negative emotions. Positive affect words include feelings like interested, excited, strong, inspired, and determined, among others, whereas negative affect words include emotions such as distressed, upset, scared, irritable, and ashamed. Although the PANAS-X would typically give people a choice to rate their feelings based on the past few weeks, this specific study let participants rate their current/present emotions. This rating was done using a 5-point Likert scale, wherein each word was given a score of 1 (very slightly or 
not at all) to 5 (extremely), indicating the intensity to which they are experiencing each emotion. Certain items fall under either the positive affect, or negative affect category, and these are tallied accordingly, with higher sums indicating higher levels of positive or negative affect. In this study, the PANAS- $X$ was administered twice - before and after the expressive writing task. Reliability of the subscales were as follows: Negative Affect Pre-Writing Task $(\alpha=.81)$, Negative Affect Post-Writing Task $(\alpha=.86)$, Positive Affect Pre-Writing Task $(\alpha=.92)$, and Positive Affect Post-Writing Task $(\alpha=.93)$.

\section{Stress Questions}

Participants were asked to think about and identify a current or most recent stressful experience and then note if they are still currently experiencing their stressor. After that, 3 questions probing about different aspects of the stressor were asked pertaining to how much impact the stressor has on their emotions and daily functioning. The first question was, “Thinking about the stressor now, how would you rate how you feel about it?" A 5-point Likert scale was used to rate their emotions, from 1 (extremely positive) to 5 (extremely negative). The second question stated, "This stressful situation caused me pain and/or distress," to which participants rated their level of agreement from 1 (strongly disagree) to 5 (strongly agree). Lastly, the third question asked, "How much has this stressor interfered with your daily life?" wherein ratings ranged from 1 (very slightly or not at all) to 5 (extremely). Higher scores for each of these items indicated a more negative impact of the stressor to the individual.

\section{Inclusion of the Stressor in the Self}

A modified version of the Inclusion of Other in the Self Scale (IOS; Aron, Aron, \& Smollan, 1992) was used to achieve the second goal of the study. The modified IOS asks participants to identify their relationship to the stressor at the current moment, marked by how 
close or distant they feel to their stressor. To fulfill this, they were asked to circle one of the seven figures shown to them, wherein each figure had varying degrees of overlap with each other. For instance, the first figure showed no overlap between me and the stressor, which indicates a separation between the person and the stressful situation. The final figure showed a significant amount of overlap in the relationship, indicating that the stressor is considered as part of the current self. This item was given to participants before and after the expressive writing task. This item is scored from 1 to 7 , such that 1 indicates very little overlap between the self and the stressor, and 7 indicates maximum overlap.

\section{Insight Questions}

To measure insight gained from the expressive writing task, 8 questions $(\alpha=.82)$ were asked about the degree to which participants gained a better understanding and a deeper insight into their stressful experience. A 5-point Likert scale ranging from 1 (strongly disagree) to 5 (strongly agree) was used to rate the strength of their agreement to the following statements: "I understand my stressor in a better way"; "I gained new insight about my stressor"; "I realized new things about myself and/or my stressor"; "I did not learn anything new about my stressor"; "I understand more about my stressor than I did before"; "I have the same amount of insight into my stressor as I did before"; "I realize important new things about my stressor"; and "My understanding of my stressor has not changed". When interpreting these scores, the fourth, sixth, and eighth items were reverse scored. Higher scores are interpreted as higher levels of postwriting insight gained, based on self-report.

\section{Adapted Strategies Questionnaire}

The original Strategies Questionnaire was developed by Ehring et al. (2010) to measure state emotion regulation, or the emotion regulation strategies individuals use at the time of the 
experiment. It specifically assesses the degree to which participants used suppression and reappraisal while engaging in the task and the time shortly after that. There are two items to be rated on a 7-point Likert scale for evaluating the use of suppression ("I tried not to let my feelings show" and "I tried to suppress my emotions") and two for reappraisal ("I thought about the film in a way that helps me to experience less emotion" and "I tried to adopt an unemotional attitude toward the film"). Since the original study where these questions were applied used a film-watching task to measure use of suppression or reappraisal, the questions were reworded to fit the current study. Although reappraisal is the focus of the study, the suppression questions were asked as well, and they were modified as follows: “As I was writing, I tried to suppress my emotions towards the event I was writing about" and "I tried not to let my feelings show in my writing". The reappraisal questions were reworded as follows: "I wrote about the event in a way that helps me to experience less emotion" and "I tried to adopt an unemotional attitude towards my writing". In addition to these questions, 6 rephrased questions from the Emotion Regulation Questionnaire (ERQ; Gross \& John, 2003) were used to measure reappraisal. The statements were reworded to focus on their use of reappraisal during the specific writing task, and they are as follows: "While writing, I controlled my emotions by changing the way I thought about the situation"; "To feel less negative emotion (such as sadness or anger), I changed the way I thought about the situation, as I was writing"; "I changed what I was thinking about while writing to feel more positive emotion (such as joy or amusement)"; "When writing about the stressful situation, I thought about it in a way that helped me stay calm"; "I changed what I was thinking about while writing to feel less negative emotion"; and "To feel more positive emotion, I changed the way I thought about the situation as I was writing". Participants were asked to rate these items from 1 (strongly disagree) to 7 (strongly agree). Only the last 8 items pertaining to 
reappraisal during the writing task were included in the analysis, and scores from this set of items showed a reliability coefficient of $\alpha=.89$.

\section{LIWC}

The Linguistic Inquiry and Word Count software was described earlier as a tool that looks into specific word types and computes the percentage of total words that belong to several linguistic categories (Pennebaker \& Chung, 2011). In analyzing the written texts to be produced by participants in this study, of particular interest were the linguistic categories for first-person pronouns and third-person pronouns. Using the LIWC allowed for a manipulation check that looked into the appropriate usage of first-person and third-person pronouns for each of the expressive writing groups.

\section{Procedure}

As each of the participants entered the laboratory, they were asked to first provide informed consent for their participation in research, and then they were instructed to fill out the first form, containing the demographic questions, and the Positive and Negative Affect Schedule - Expanded Form (PANAS-X; Watson \& Clark, 1999). The same form also contained instructions to think about a recent or current stressful situation they have experienced and questions to answer regarding this stressor. Finally, participants were asked to answer the modified version of the Inclusion of Other in the Self Scale (IOS; Aron, Aron, \& Smollan, 1992).

After completing this first questionnaire, participants were asked to engage in a 15minute expressive writing task, wherein they were randomly assigned to either the first-person writing condition or the third-person writing condition. The first-person writing condition asked participants to follow the instructions stated below:

For the next 15 minutes, use the computer to write about the current or most recent stressor that you wrote about in the questionnaire, as well as your thoughts and 
feelings about it. Write about your stressor as you experience it, using your own perspective (using first person pronouns such as I, me, and my). So in other words, acknowledge that you are experiencing your stressor. As you write, you may use statements such as 'I feel ' and 'This happened to me'. It is important that you write continuously for 15 minutes. Do not worry about spelling or grammar. If you run out of things to write about, just repeat what you have already written.

On the other hand, the third-person writing condition asked participants to do the

following:

For the next 15 minutes, use the computer to write about the current or most recent stressor that you wrote about in the questionnaire, as well as your thoughts and feelings about it. Write about your stressor as if another person experienced it, and write it from this person's perspective (using third person pronouns such as he, she, it, his, her, they). So in other words, pretend that someone else is experiencing your stressor. As you write, you may use statements such as ' $\mathrm{He} / \mathbf{s h e}$ feels___ and 'This___ happened to him/her'. It is important that you write continuously for 15 minutes. Do not worry about spelling or grammar. If you run out of things to write about, just repeat what you have already written.

For this expressive-writing task, participants were directed to use the computer to type their essays.

After the writing task, they were tasked to answer the second questionnaire, which contained the PANAS-X again, as well as the Insight Questions. Participants were asked questions from the Adapted Strategies Questionnaire (Ehring et al., 2010) as well as the additional reworded questions from the Emotion Regulation Questionnaire (ERQ; Gross \& John, 2003). Lastly, the modified version of the Inclusion of Other in the Self Scale (IOS; Aron, Aron, $\&$ Smollan, 1992) was asked again, to measure participants' relationship to their stressor after the 15-minute writing task. 


\section{CHAPTER IV}

\section{RESULTS}

\section{Stressor Questions}

When examining the first stressor question, which asked about the extent of positive or negative emotions brought about by the stressor, the total sample reported a mean of 3.53 and a standard deviation of .78. The second stressor question, which examined pain and/or distress, resulted in the following: $M=3.45, S D=1.10$. Finally, the third stressor question looked into the degree by which the stressor interfered with daily life $(M=3.28, S D=1.09)$. As observed, the average negative impact of the stressor in terms of emotions, pain or distress, and interference with daily life is not too far from the neutral mark - a score of 3. This may imply that although they are slightly leaning towards the negative, the stressors identified by the participants are not perceived as extremely debilitating to them. Browsing through their responses, it appears as if most participants identified academic-related concerns (e.g. finals, GPA, group projects) as their current main stressors.

\section{Manipulation Check}

In this study, LIWC was used to serve as a manipulation check on whether or not participants correctly used their assigned pronouns (I and we versus he/she and they). An independent samples $t$-test was conducted for the first person pronoun I. Significant differences were found between the first person condition $(M=11.49, S D=1.95)$ and the third person condition $(M=.06, S D=.17), t(62)=32.93, p<.001$. This can confirm that for the most part, participants under the first person condition appropriately used first person pronouns in their writing task. 
Another independent-samples $t$-test was conducted for the third person pronouns he/she. Significant differences were found between the first person condition $(M=.86, S D=1.540)$ and the third person condition $(M=10.83, S D=4.07), t(62)=-12.93, p<.001$. This can show that generally, individuals in the third person condition used the third person pronouns $h e$ and/or she. It should be noted that for both instances, percentages of word usage was noted, rather than the actual word count.

\section{First Person Descriptives and Correlations}

As shown in Table 1 below, significant correlations were found between variables in the first person condition $(n=32)$. Reappraisal was positively correlated to negative affect before the writing task. This correlation was between a moderate to large effect, and it implies that higher negative affect before engaging in the writing task is associated with higher levels of reappraisal in individuals during the writing activity. Significant correlations were also found between reappraisal and insight, showing a moderate to large effect. Higher reappraisal levels during the writing task is positively correlated to higher levels of insight. Significant positive correlations were also found between positive affect before and after the writing task, and between negative affect before and after the writing task. Both large effects show that higher negative or positive affect before the writing task is associated with higher negative or positive affect after the writing task, respectively. The perceived inclusion of the stressor in the self before the writing task was negatively correlated to positive affect before writing, which means that the more included one's stressor is to the self, the lower the positive affect was before the writing task. The perceived inclusion of the stressor in the self after the writing task was significantly correlated to several variables, including reappraisal, positive affect before the writing task, positive affect after the writing task, negative affect after the writing task, and perceived 
inclusion of the stressor in the self before the writing task. Taking it one by one, this implies that the more included the stressor is in the self after the writing task, the lower the reappraisal levels were while writing. Greater inclusion of the stressor to the self after the writing task was also associated with lower positive affect before and after the writing task, as well as higher negative affect after the writing task. Finally, a greater perceived inclusion of the stressor to the self after the writing task was related to greater perceived inclusion of the stressor to the self before the writing task.

Table 1

Correlations, Means and Standard Deviations for the First Person Condition $(n=32)$

\begin{tabular}{|c|c|c|c|c|c|c|c|c|}
\hline Variable & 1 & 2 & 3 & 4 & 5 & 6 & 7 & 8 \\
\hline 1. Reappraisal & -- & & & & & & & \\
\hline 2. Insight & $.48 * *$ & -- & & & & & & \\
\hline 3. Positive Affect (Pre) & .05 & .19 & -- & & & & & \\
\hline 4. Positive Affect (Post) & .09 & .30 & $.82 * *$ & -- & & & & \\
\hline 5. Negative Affect (Pre) & $.35^{*}$ & .30 & -.08 & .20 & -- & & & \\
\hline $\begin{array}{l}\text { 6. Negative Affect } \\
\text { (Post) }\end{array}$ & .18 & .15 & -.06 & .01 & $.69 * *$ & -- & & \\
\hline 7. Inclusion (Pre) & -.09 & .20 & $-.39 *$ & -.25 & .21 & .28 & -- & \\
\hline 8. Inclusion (Post) & $-.35^{*}$ & -.17 & $-.50 * *$ & $-.46 * *$ & .20 & $.35^{*}$ & $.58 * *$ & -- \\
\hline$M$ & 25.85 & 28.85 & 25.81 & 23.11 & 15.72 & 17.41 & 5.03 & 4.50 \\
\hline$S D$ & 11.02 & 6.07 & 9.24 & 8.95 & 6.40 & 7.08 & 1.36 & 1.65 \\
\hline
\end{tabular}


Table 2

Correlations, Means and Standard Deviations for the Third Person Condition $(n=32)$

\begin{tabular}{lcccccccc}
\hline Variable & 1 & 2 & 3 & 4 & 5 & 6 & 7 & 8 \\
\hline 1. Reappraisal & -- & & & & & & & \\
2. Insight & .09 & -- & & & & & & \\
3. Positive Affect (Pre) & -.12 & .12 & -- & & & & & \\
4. Positive Affect (Post) & -.00 & .09 & $.81 * *$ & -- & & & & \\
5. Negative Affect (Pre) & .17 & .04 & -.07 & -.10 & -- & & & \\
6. Negative Affect (Post) & .09 & .16 & -.14 & $-.39 *$ & $.62 * *$ & -- & & \\
7. Inclusion (Pre) & .01 & -.28 & -.24 & -.20 & .07 & .01 & -- & \\
8. Inclusion (Post) & -.15 & $-.52 * *$ & -.24 & -.25 & .01 & .10 & $.79 * *$ & -- \\
$M$ & 24.65 & 27.15 & 24.72 & 19.63 & 16.21 & 18.75 & 4.78 & 4.47 \\
$S D$ & 10.17 & 4.97 & 9.37 & 10.43 & 4.85 & 7.04 & 1.45 & 1.77 \\
\hline * $p<.05 ; * * p<.01$ & & & & & & & &
\end{tabular}

\section{Third Person Descriptives and Correlations}

For the third person condition, Table 2 shows a significant negative correlation between positive affect and negative affect after the writing condition. This moderate to large effect implies that higher positive affect is associated with lower negative affect, and vice versa. Similar to the first condition, significant positive correlations were also found between positive affect before and after the writing task, and between negative affect before and after the writing task. These large effects imply that higher positive affect before writing is associated with higher positive affect after writing, and that higher negative affect before writing is associated with 
higher negative affect after writing. Significant negative correlations were also found between the perceived inclusion of the stressor in the self after the writing task and insight. This shows that more inclusion of the stressor in the self after the writing task is associated with lower insight gained after writing. Finally, perceived inclusion of the stressor in the self before the writing task was positively correlated to perceived inclusion of the stressor in the self after writing.

\section{Correlations for Total Sample}

When looking at the total sample, several significant correlations between variables were also found, as shown in Table 3. Reappraisal during writing was positively correlated to insight gained. Reappraisal during writing was also positively correlated to negative affect before the writing task. Positive affect before the writing task was positively correlated to positive affect after the writing task. The same was true for negative affect, where negative affect before and after the writing task were positively correlated. Perceived inclusion of the stressor in the self before the writing task was negatively correlated to positive affect before the writing task. This implies that greater inclusion of the stressor in the self before writing was associated with lower positive affect. Perceived inclusion of the stressor in the self after writing was positively correlated to perceived inclusion of the stressor in the self before the writing task. In addition, perceived inclusion of the stressor in the self after the writing task was negatively correlated to several variables, including reappraisal during writing, insight, positive affect before writing, and positive affect after writing. 
Table 3

Means, Standard Deviations, and Correlations for all Variables $(N=64)$

\begin{tabular}{|c|c|c|c|c|c|c|c|c|c|}
\hline Variable & 1 & 2 & 3 & 4 & 5 & 6 & 7 & 8 & 9 \\
\hline 1. Condition & -- & & & & & & & & \\
\hline 2. Reappraisal & -.06 & -- & & & & & & & \\
\hline 3. Insight & -.15 & $.32 *$ & -- & & & & & & \\
\hline $\begin{array}{l}\text { 4. Positive } \\
\text { Affect (Pre) }\end{array}$ & -.06 & -.03 & .16 & -- & & & & & \\
\hline $\begin{array}{l}\text { 5. Positive } \\
\text { Affect (Post) }\end{array}$ & -.18 & .05 & .21 & $.81 *$ & -- & & & & \\
\hline $\begin{array}{l}\text { 6. Negative } \\
\text { Affect (Pre) }\end{array}$ & .04 & $.28 *$ & .19 & -.08 & .05 & -- & & & \\
\hline $\begin{array}{l}\text { 7. Negative } \\
\text { Affect (Post) }\end{array}$ & .10 & .13 & .14 & -.11 & -.21 & $.66 * *$ & -- & & \\
\hline $\begin{array}{l}\text { 8. Inclusion } \\
\text { (Pre) }\end{array}$ & -.09 & -.04 & -.01 & $-.31 *$ & -.21 & .14 & .13 & -- & \\
\hline $\begin{array}{l}\text { 9. Inclusion } \\
\text { (Post) }\end{array}$ & -.01 & $-.26^{*}$ & $-.32 *$ & $-.36 * *$ & $-.34 * *$ & .12 & .23 & $.69 * *$ & -- \\
\hline$M$ & 1.50 & 25.24 & 28.00 & 25.27 & 21.37 & 15.97 & 18.08 & 4.91 & 4.48 \\
\hline$S D$ & .50 & 10.54 & 5.57 & 9.25 & 9.80 & 5.64 & 7.04 & 1.40 & 1.70 \\
\hline
\end{tabular}

Note: Condition was coded as follows: 1: First Person Condition and 2: Third Person Condition.

\section{First Hypothesis: Reappraisal}

The first goal of the study aimed to look into group differences of reappraisal. An independent samples $t$-test revealed no significant differences in levels of reappraisal during the writing task between the first person condition $(M=25.83, S D=11.02)$ and the third person 
condition $(M=24.65, S D=10.17), t(62)=.45, p=.92$. The hypothesis that third person writing would result in higher reappraisal levels was not supported in the study.

\section{Second Hypothesis: Inclusion of the Stressor in the Self}

The second hypothesis investigated any differences in perceived inclusion of the stressor in the self between the first person and the third person condition. A repeated-measures analysis of variance (ANOVA) showed a significant main effect for time on perceived inclusion of the stressor in the self, $F(1,58)=7.34, p=.009$, but no significant interaction between inclusion and condition, $F(1,58)=.38, p=.54$.

An analysis of covariance (ANCOVA) was also conducted and no significant differences were found between inclusion of the stressor in the self ratings before and after writing, when adjusting for inclusion of the stressor in the self before writing, $F(1,59)=.25, p=.62$.

\section{Third Hypothesis: Affect}

The third hypothesis looked into the impact of first- versus third-person writing on an individual's affect. Repeated-measures ANOVA revealed a significant main effect of time on negative affect, $F(1,62)=9.71, p<.01$. However, negative affect before and after the writing task did not show significant differences when participants wrote either in the first person or third person conditions, $F(1,62)=.39, p=.54$. An ANCOVA was also run and no significant differences were found between negative affect before and after the writing task, $F(1,61)=.48, p$ $=.49$, while adjusting for negative affect before writing.

When looking at positive affect, repeated-measures ANOVA shows a significant main effect for time on positive affect, $F(1,62)=28.88, p<.01$. Similar to negative affect, there was no interaction found between the condition (first person versus third person) and positive affect, $F(1,62)=2.72, p=.10$. When I ran an ANCOVA, no significant differences were found 
between positive affect before and after the writing task, $F(1,61)=3.23, p=.07$, when adjusting for positive affect before writing.

\section{Fourth Hypothesis: Insight}

The study looked into any differences in insight gained between the two writing conditions. An independent samples t-test showed no significant differences between the first person condition $(M=28.85, S D=6.07)$ and the third person condition $(M=27.15, S D=4.97)$, $t(62)=1.22, p=.16$. The hypothesis that writing in the third person would lead to better insight was not supported by the results of the study.

\section{Final Hypothesis: Mediational Model}

The final goal of the study aimed to look into the possible mediational role of reappraisal between expressive writing and its outcomes in post-writing affect and insight. The software LISREL was used to generate data shown in the path analysis model in Figure 5 in the following page. As we can observe in the model, pre-writing positive affect significantly predicted postwriting positive affect. The same positive relationship is observed in a significant prediction between pre-writing and post-negative affect. There was also a significant path found between reappraisal and post-writing insight, suggesting that the more reappraisal was employed while writing about the stressor, the more insight an individual has gained after writing. As observed, no other significant relationships were found, which shows that my final hypothesis of reappraisal as a mediator between first- or third-person writing and outcomes including affect and insight, is not supported. 


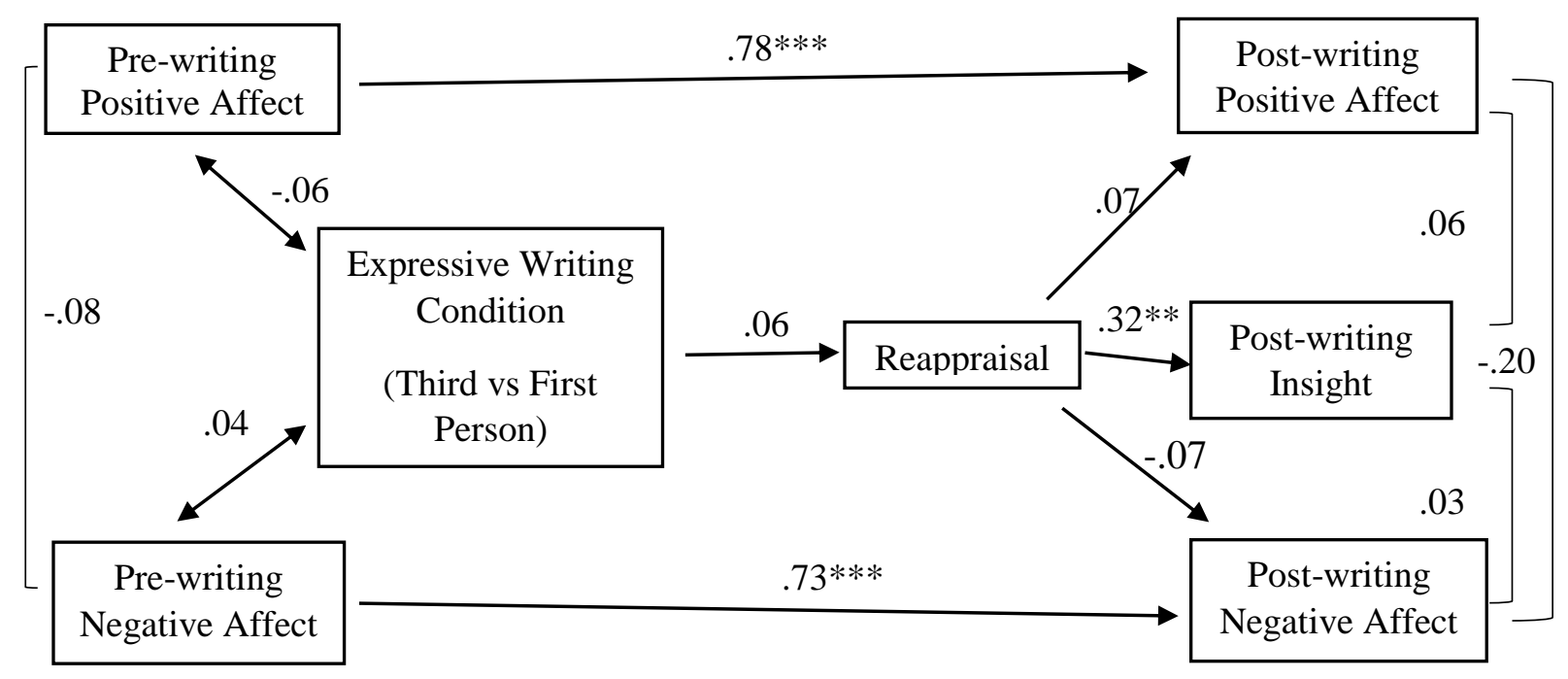

Figure 2. Path analysis model generated by the LISREL software. The Beta $(\beta)$ values are included in the diagram.

$* * p<.01, * * * p<.001$ 


\section{CHAPTER V}

\section{DISCUSSION}

The study aimed to look at the role of reappraisal in expressive writing either in the first person or third person, and its outcomes in affect and insight. The first goal of the study investigated any differences in reappraisal between the first person and third person, and the results showed that people who wrote in the third person did not reappraise more while writing than people who wrote in the first person. This means that, contrary to what was hypothesized, writing about one's stressful situation in the third person does not necessarily mean that one changes how they think about a situation, or shifts in the meanings they attribute to it (Lepore, Greenberg, Bruno, \& Smyth, 2002; Wang, et al., 2015). Since the LIWC manipulation check showed an appropriate use of pronouns assigned to participants, it is highly unlikely that an error in pronoun use resulted in this outcome.

Although it was originally assumed that by writing in the third person, people will change the way they think about their situation; it is possible that people wrote only as they were instructed, which is to imagine as if another person is experiencing their stressor. Assigning a different person as the new 'recipient' of their stressor did not automatically imply that they took an outsider's perspective and objectively viewed their situation. It is possible that they only changed the ownership of the stressor, rather than reframing how they viewed their own situation, thus restricting the likelihood that reappraisal took place. It is difficult to particularly determine what went through each participant's mind while they spoke of their stressor from another person's perspective, but changing the 'main character' in the narrative was probably different from completely changing the meanings and evaluations behind the event, which reappraisal entails (Wang et al, 2015). 
Another possible explanation for the lack of group differences in reappraisal between first-person and third-person writing can probably be attributed to how participants began writing in one perspective and remained writing in that frame of mind (i.e., people only wrote purely in the first person or third person). Previous studies showed that changes in perspective were found when people shifted from first person to second person to third person (Jin, 2005; Seih et al., 2008). It is possible that to achieve an objective and distant perspective, individuals need to go through the entire process of shifting from one pronoun type to another in order to achieve changes in the way they viewed their stressful situation. In other words, it is possible that using third person pronouns is not the key to reappraising, but rather, the process of shifting from first person to second and third person.

Lastly, it is also possible that rather than writing with a specific type of pronoun, other factors have a larger influence on one's ability to reappraise during a task. For instance, people's tendencies to use reappraisal in regulating emotions might have a stronger impact on their use of reappraisal while engaging in expressive writing, than using the third person. These tendencies to use reappraisal may also be influenced by other factors, such as having depressive symptoms. People with depression, for instance, have been found to not only have higher levels of suppression, but also lower levels of reappraisal (D’Avanzato, Joormann, Siemer, \& Gotlib, 2013). Such tendencies to reappraise less may impact their ability to reappraise when writing, regardless of pronouns used.

The second goal of the study looked into any group differences in the perceived inclusion of the stressor in the self between the first person and the third person condition. No interaction between experimental condition and time was found, which showed that the change in the perceived inclusion of the stressor in the self, did not vary as a function of whether the person 
used first person or third person pronouns in writing. However, the study showed a main effect; through time, people were able to lower their perceived inclusion of the stressor in the self, and in essence, see their stress as less a part of them after writing. This finding seems to point to a new possible positive outcome that expressive writing as a whole can bring about. By simply writing about one's stressors, people can distance themselves more from them. This might be due to the cathartic expression of emotions that happen when one engages in expressive writing (Pennebaker \& Chung, 2011). It might also be due to the act of giving verbal labels to these emotional experiences, which allows people to process the stressor and give meaning to the emotions behind it (Pennebaker \& Chung, 2011). It would be interesting to see what specific aspects of expressive writing allow for people to distance themselves from the stressor. It is possible that simply typing/writing it down allows them to physically see the stressor move away from them towards another tool (e.g., a piece of paper or a laptop screen), or it might be due to underlying emotional and cognitive processes that may be of interest for future researchers to investigate further.

When looking simply at the relationships between the perceived inclusion of the stressor in the self and other variables in the study, several significant correlations were found, regardless of condition. The results showed that the more included the stressor is in the self after writing, the lower their tendencies to reappraise during the writing task was. This makes sense, since if a person views the stressful situation as part of themselves, it seems more challenging to take another perspective and modify their perception towards it, which is what reappraisal is (Gross, 2002). In addition, the results showed that the higher the perceived inclusion of the stressor in the self is, the lower insight they reported gaining, and the lower their positive affect was before and after writing. Since they perceived their stressor as close to them, this seems to be contrary to the 
psychological displacement that occurs when one shifts in psychological distance from one's stressful experiences to an objective evaluation of the event (Jin, 2005). With the lack of distance and objectivity from the stressor, it is understandable that less insight and lower positive affect also accompany it.

The third goal of the study was to investigate the impact of writing in the first person and third person on an individual's post-writing affect, and to specifically determine which condition leads to a more favorable affect. The results showed that for both negative and positive affect, there were no differences between people that used first person or third person pronouns. However, through time, it was shown that people showed a decrease in positive affect and an increase in negative affect. Regardless of pronouns used in writing, the act itself of writing about a stressful event led to a less favorable affect, which is aligned to previous evidence showing the negative short-term outcomes of expressive writing (Baikie \& Wilhelm, 2005). An increase in negative mood and a decrease in positive mood has been shown to be a typical result of expressive writing, since only a short time is allotted for disclosing about upsetting experiences (Pennebaker, Kiecolt-Glaser, \& Glaser, 1988). In addition, there is only a minimal space given for processing these negative events, without a follow-up of support from others or coping skills to use in dealing with it.

The fourth goal looked into insight, and whether there were any differences in insight gained between first person and third person writing. No differences were found between conditions, which makes sense given that the assumption used to justify this hypothesis was also unsupported. Writing in the third person did not lead to reappraisal, which was predicted to be the mechanism that would supposedly lead to greater insight towards one's stressful situation, since a person is assumed to shift towards an outsider's perspective and take a step back from the 
situation (Jin, 2005; Lepore, Greenberg, Bruno, \& Smyth, 2002; Pennebaker \& Chung, 2011; Seih et al., 2008; Wang, et al., 2015). It is interesting to note though, that when observing correlations, insight and reappraisal are significantly correlated in the first person condition, but are not significantly correlated in the third person condition. This means that when writing from a first person perspective - which is typically how expressive writing works - the more the person reappraises during writing, the more insight s/he gains. This makes sense in light of previous evidence that show how cognitively organizing one's situation can widen one's understanding of their experience (Pennebaker \& Chung, 2011). Since people in the midst of stress may have limited opportunities to examine their lives, engaging in expressive writing provides them the space to reflect and process the emotional experiences they are going through. The same results were probably not found in the third person condition since by changing the main character in the narrative, as we mentioned earlier, the ownership of the stressful event shifts. This change in perspective might hinder the person from fully reflecting and processing their own stressful event, thus lessening the opportunity to gain insight on one's stressor.

Finally, the study examined whether reappraisal mediates the relationships between expressive writing and its outcomes in post-writing affect and insight. The path model does not show any mediating effects for reappraisal, and this is not surprising, given the lack of significant differences between the first person and third person condition in their use of reappraisal during writing, and the minimal amount of significant correlations among variables. As previously mentioned, it is possible that using third person pronouns is not the key mechanism by which people reappraise during a writing task. Other factors may play a stronger role in bringing about reappraisal while writing about stressful experiences, including trait 
reappraisal, shifting perspectives from one pronoun to another in one sitting, or even explicitly telling individuals to change how they think about their stressor.

In sum, the study, first of all, showed that writing in the third person did not immediately lead to greater reappraisal in individuals. Second, the study showed that through time, people were able to lower their perceived inclusion of the stressor in the self, and in a way, distance themselves from their stressor by writing. Additionally, the more included the stressor is in the self after writing, the lower their tendencies to reappraise during the writing task was, the lower insight they reported gaining, and the lower their positive affect was before and after writing. Third, it was shown that, through time, people generally showed a decrease in positive affect and an increase in negative affect. Fourth, writing in the third person did not lead to greater insight. However, reappraisal was positively correlated to insight when people wrote in the first person. Finally, reappraisal was not shown to be a mediator between expressive writing and its outcomes in affect and insight.

\section{Limitations and Future Directions}

Although aspects of the study's results seem promising, the study was limited due to several factors, which may be of interest for some researchers to consider in future studies. First of all, the outcomes measured in the study were limited to short-term outcomes (i.e., immediate measures of insight and affect). In previous expressive writing studies, ideal conditions include writing at least 3 times, with a preferred 1-2 day interval between writing (Pennebaker, 2010). In this study, participants were only limited to writing once, and outcomes were immediately measured after they wrote, which may have made a difference in the results produced. It would be interesting to see the effects of first person versus third person writing if participants were asked to write more than once, and if we were able to measure outcomes over a longer period of 
time. For instance, how different would affect and insight be when these are measured over a few days, where various emotional and cognitive processes may take place and influence individuals' abilities to regulate emotions and understand their stressful situations? It is possible that with repeated writing, people get habituated to the stressors, and find an elevation in positive affect over time (Lepore, Greenberg, Bruno, \& Smyth, 2002). In addition, the more people write over time, they may also gain more insight, as they change their thoughts regarding the stressful situation they are describing (Lepore, Greenberg, Bruno, \& Smyth, 2002).

Another possible limitation of the study is the lack of a precise measure as to how people actually used third person pronouns when writing. There may have been some individual differences in writing with the third person. For instance, when people were instructed to imagine that their stressor happened to another person, some people may have thought of actual people, while others may not have pictured a real person they know of. For those who had actual people in their mind, people may have also varied in their degree of closeness and relationship to this person. For example, some people may have thought of a friend or a loved one, while some may have thought of a more distant relative or acquaintance. These individual differences might contribute to a lack of understanding as to how exactly the third person writing condition was used. For future studies, then, it would seem apt to refine the instructions used for the third person condition, wherein variety in answers can be addressed and minimized.

In addition, there seems to be a need to explore possible moderators that influence reappraisal during expressive writing. As mentioned earlier, one's natural and spontaneous manner of regulating emotions might play a larger role in one's ability to reappraise during a writing task, rather than simply engaging in the task that induces such a response. Different aspects of a person's emotion regulation tendencies, for example how they might typically 
suppress emotions, may also be worth examining, to see how these impact expressive writing behaviors. Closely tied to this, other moderators, such as depressive symptoms, may also moderate effects of expressive writing in affect and insight. Previous research has shown that people with depression show an elevated use of first person singular pronouns (Pennebaker, Mehl, \& Niederhoffer, 2003). It would be interesting to compare how these samples might respond to engaging in a third person writing condition, where they are challenged to depart from their typical tendencies in writing. In addition, depressed individuals are generally marked with high levels of rumination and suppression, and low levels of reappraisal (D'Avanzato, Joormann, Siemer, \& Gotlib, 2013), which might influence their ability to reappraise in a writing task.

Since the mediating effect of reappraisal between expressive writing and its outcomes was not shown, future researchers may want to turn their attention towards measuring other possible mediators that explain expressive writing and its outcomes. It may be interesting for researchers to take a look at the use of positive emotion words generated by the LIWC software as a possible mediator, given previous evidence that higher use of positive emotions words is correlated with improved health (Pennebaker \& Chung, 2011). One’s ability to cognitively organize an event might also be a possible mediator to look into, since past research has shown how cognitive organization marked by causal and insight word use, is linked with a positive reappraisal of an event (Pennebaker \& Chung, 2011).

In line with looking further at specific word types included in the texts participants write, it may also be interesting to explore any changes in discrete emotions (e.g. shame, guilt) that took place. Negative affect is a broad concept that does not capture specific aspects of emotions that might change, such as guilt and shame - two emotions which also tend to be very selffocused. 
Like any other study that relies on self-report for measuring outcomes, our study may be limited by individual biases that surround using questionnaires as a measure for affect, insight, and use of reappraisal. Other means of strengthening the validity of these tools may be of interest to future researchers, such as using physiological markers to measure changes in affect, on top of self-report questionnaires. Our sample was also limited to a small number of participants from a predominantly White university. A larger and more diverse sample in aspects such as gender, ethnicity, and educational background may present a more varied response that is representative of other groups of people. It should also be noted that 64 participants is underpowered for mediation, so increasing the sample size will be beneficial for future studies. Finally, given that the participants were college students and most of their identified stressors were academicrelated, it would be interesting to see how expressive writing may pan out for other types of stressors, such as trauma from the past or chronic mental health conditions that a person has to regularly deal with. Previous research has shown that expressive writing creates more positive benefits when the nature of stress and trauma is clinically more severe (Baikie \& Wilhelm, 2005), so going beyond academic stressors may be worth looking into.

\section{Implications of the Study}

To the author's knowledge, no studies have yet been conducted linking reappraisal to expressive writing. Expressive writing has long been shown to provide positive outcomes; however, the mechanisms behind it remain to be found. This study provides an initial step towards further exploration in this area. Although this study found that third person writing does not necessarily lead to more reappraisal in individuals, it would be worth looking at other ways that emotion regulation processes might be associated with expressive writing. 
The study was able to find that simply writing about one's stressors can allow people to distance themselves from it. Although it would be worth exploring if it was the mere act of expressive writing that led individuals to distance from the stressor, or if it was due to time or history effects, the results of the study suggest that people can use writing as a tool when they are so consumed by their stressor, and they would like to rid themselves from its impact. Clinically, it might be of benefit for counselors to use expressive writing as a way for clients to view themselves as separate from the stress they are experiencing, which may allow them to perceive and deal with it more effectively.

The study also showed that writing once about one's stressor can make an immediate change in emotion, such that people feel less positive affect and more negative affect after writing. Although experiencing such distress is not ideal, such change in affect might be key for some individuals to realize that they have a problem that needs to be dealt with. People who are not mindful of the challenges that surround them, or people who blatantly deny their need to make a change, might benefit from a shift in emotions that brings them to awareness of something they may need to work on. The ability of feeling negatively after writing about something stressful may be used as a tool by clinicians for clients to be motivated to take action. Linking these two ideas together, the study results seem to suggest that individuals that engage in expressive writing may experience a form of dialectic - wherein they feel less attached and bound to their stressor (i.e. more distance from the stressor), but also feel more negative affect and less positive affect towards it (i.e. stronger negative emotional attachment to it). Experiencing both ends might lead individuals to a place where they are distressed enough to want to make a change, but not debilitated enough to prevent them from action. For instance, if a person writes about the stress of maintaining a high GPA, as some of our participants did, they 
may feel negative emotions that give rise to their need to attend to it, but they also feel a distance from it, that might better equip them to take action. Overall, this study adds and contributes new findings to the limited body of literature concerning this topic, and offers possible areas for future consideration in research and clinical practice. 


\section{REFERENCES}

Alparone, F. R., Pagliaro, S., \& Rizzo, I. (2015). The words to tell their own pain: Linguistic markers of cognitive reappraisal in mediating benefits of expressive writing. Journal of Social and Clinical Psychology, 34, 495-507. doi:10.1521/jscp.2015.34.6.495

Aron, A., Aron, E. N., \& Smollan, D. (1992). Inclusion of other in the self scale and the structure of interpersonal closeness. Journal of Personality and Social Psychology, 63, 596-612.

Baikie, K. A., \& Wilhelm, K. (2005). Emotional and physical health benefits of expressive writing. Advances in Psychiatric Treatment, 11, 338-346.

Brody, L. R. (2000). The socialization of gender differences in emotional expression: Display rules, infant temperament, and differentiation. In A. H. Fischer (Ed.), Gender and emotion: Social psychological perspectives (pp. 24-47). New York: Cambridge University Press.

Brown, R. T. (1992). Helping students confront and deal with stress and procrastination. Journal of College Student Psychotherapy, 6, 87-102.

Campbell, R. S., \& Pennebaker, J. W. (2003). The secret life of pronouns: Flexibility in writing style and physical health. Psychological Science, 14, 60-65.

Chung, C., \& Pennebaker, J. (2007). The psychological functions of function words. In Fiedler, K. (Ed.), Social Communication (pp. 343-359). New York: Psychology Press.

D’Avanzato, C., Joormann, J., Siemer, M., \& Gotlib, I.H. (2013). Emotion regulation in depression and anxiety: Examining diagnostic specificity and stability of strategy use. Cognitive Therapy and Research, 37, 968-980. doi:10.1007/s10608-013-9537-0

Ehring, T., Tuschen-Caffier, B., Schnulle, J., Fisher, S., \& Gross, J. (2010). Emotion 
regulation and vulnerability to depression: Spontaneous versus instructed use of emotion suppression and reappraisal. Emotion, 10, 563-572. doi:10.1037/a0019010

Frattaroli, J. (2006). Experimental disclosure and its moderators: A meta-analysis. Psychological Bulletin, 132, 823-865. doi:10.1037/00332909.132.6.823

Frisina, P. G., Borod, J. C., \& Lepore, S. J. (2004). A meta-analysis of the effects of written emotional disclosure on the health outcomes of clinical populations. The Journal of Nervous and Mental Disease, 192, 629-634. doi:10.1097/01.nmd.0000138317.30764.63

Gross, J. J. (1998). The emerging field of emotion regulation: An integrative review. Review of General Psychology, 2, 271-299. doi:10.1017.S0048577201393198

Gross, J. J. (2002). Emotion regulation: affective, cognitive, and social consequences. Psychophysiology, 39, 281-291. doi:10.1017.S0048577201393198

Gross, J. J. (2015). Emotion regulation: Current status and future prospects. Psychological Inquiry, 6, 1-26. doi:10.1080/1047840X.2014.940781

Gross, J. J., \& Jazaieri, H. (2014). Emotion, emotion regulation, and psychopathology: An affective science perspective. Clinical Psychological Science, 2, 387-401. doi: $10.1177 / 2167702614536164$

Gross, J. J., \& John, O. P. (2003). Individual differences in two emotion regulation processes: Implications for affect, relationships, and well-being. Journal of Personality and Social Psychology, 85, 348-362. doi:10.1037/0022-3514.85.2.348

Gross, J. J., Sheppes, G., \& Urry, H. L. (2011). Emotion generation and emotion regulation: A distinction we should make (carefully). Cognition and Emotion, 25, 765781. doi:10.1080/02699931.2011.555753 
Harris, A. H. S. (2006). Does expressive writing reduce health care utilization? A meta analysis of randomized trials. Journal of Consulting and Clinical Psychology, 74, 243252. doi: 10.1037/0022-006X.74.2.243

Kacewicz, E., Pennebaker, J. W., Davis, M., Jeon, M., \& Graesser, A. C. (2013). Pronoun use reflects standings in social hierarchies. Journal of Language and Social Psychology, 33, 125-143. doi:10.1177/0261927X13502654.

Keltner, D., Gruenfeld, D. H., \& Anderson, C. (2003). Power, approach, and inhibition. Psychological Review, 110, 265-284.

Klem, L. (1995). Path analysis. In. L. G. Grimm, \& P. R. Yarnold, Reading and understanding multivariate statistics (pp. 65-97). Washington, DC: American Psychological Association.

Lepore, S. J., Greenberg, M. A., Bruno, M., \& Smyth, J. M. (2002). Expressive writing and health: Self-regulation of emotion-related experience, physiology, and behavior. In S.J. Lepore, \& J.M. Smyth (Eds.), The writing cure: How expressive writing promotes health and emotional well-being (pp. 99-118). Washington, DC: American Psychological Association.

Nazarian, D., \& Smyth, J. M. (2013). An experimental test of instructional manipulations in expressive writing interventions: Examining processes of change. Journal of Social and Clinical Psychology, 32, 71-96. doi:10.1521/jscp.2013.32.1.71

Newman, M. L., Groom, C. J., Handelman, L. D., \& Pennebaker, J. W. (2008). Gender differences in language use: An analysis of 14,000 text samples. Discourse Processes, 45, 211-236. doi:10.1080/01638530802073712

Pennebaker, J.W. (2010). Expressive writing in a clinical setting. Independent 
Practitioner, 23-25.

Pennebaker, J. W. (2011). The secret life of pronouns: What our words say about us.

New York: Bloomsbury Press.

Pennebaker, J. W., \& Beall, S. (1986). Confronting a traumatic event: Toward an understanding of inhibition and disease. Journal of Abnormal Psychology, 95, 274-281.

Pennebaker, J. W., \& Chung, C. K. (2007). Expressive writing, emotional upheavals, and health. In H. Friedman and R. Silver (Eds.), Handbook of health psychology (pp. 263284). New York: Oxford University Press.

Pennebaker, J. W., \& Chung, C. K. (2011). Expressive writing and its links to mental and physical health. In H. S. Friedman (Ed.), Oxford handbook of health psychology. New York: Oxford University Press.

Pennebaker, J. W., \& Stone, L. D. (2003). Words of wisdom: Language use over the life span. Journal of Personality and Social Psychology, 85, 291-301. doi:10.1037/00223514.85.2.291

Pennebaker, J.W., Groom, C.J., Loew, D., \& Dabbs, J.M. (2004). Testosterone as a social inhibitor: Two case studies of the effect of testosterone treatment on language. Journal of Abnormal Psychology, 113, 172-175. doi:10.1037/0021-843X.113.1.172

Pennebaker, J. W., Kiecolt-Glaser, J. K., \& Glaser, R. (1988). Disclosure of traumas and immune function: Health implications for psychotherapy. Journal of Consulting and Clinical Psychology, 56, 239-245. doi:10.1037/0022-006X.56.2.239

Pennebaker, J.W., Mehl, M.R., \& Niederhoffer, K.G. (2003). Psychological aspects of natural language use: our words, our selves. Annual Review of Psychology, 54, 547-577. doi: 10.1146/annurev.psych.54.101601.145041 
Peña-Sarrionandia, A., Mikolajczak, M., \& Gross, J.J. (2015). Integrating emotion regulation and emotional intelligence traditions: A meta-analysis. Frontiers in psychology, 6, 1-27. doi: 10.3389/fpsyg.2015.00160

Salovey, P., Mayer, J. D., Golman, S. L., Turvey, C., \& Palfai, T. P. (1995). Emotional attention, clarity, and repair: Exploring emotional intelligence using the trait meta-mood scale. In J. W. Pennebaker (Ed.), Emotion, disclosure, and health (pp. 125-154). Washington, DC: American Psychological Association.

Sapolsky, R. M. (2004). Social status and health in humans and other animals. Annual Review of Anthropology, 33, 393-418. doi: 10.1146/annurev.anthro.33.070203. 144000

Slatcher, R. B., \& Pennebaker, J. W. (2006). How do I love thee? Let me count the words: The social effects of expressive writing. Psychological Science, 17, 660-664. doi:10.1111/j.1467-9280.2006.01762.x

Smyth, J. (1998). Written emotional expression: Effect sizes, outcome types, and moderating variables. Journal of Consulting and Clinical Psychology, 66, 174-184.

Wang, F., Wang, C., Yin, Q., Wang, K., Li, D., Mao, M., Zhu, C., \& Huang, Y. (2015). Reappraisal writing relieves social anxiety and may be accompanied by changes in frontal alpha asymmetry. Frontiers in Psychology, 6, 1-11. doi: 10.3389/fpsyg. 2015.01604

Watson, D. \& Clark, L. A. (1999). The PANAS-X: Manual for the positive and negative affect schedule-expanded form. Ames: The University of Iowa. 


\title{
APPENDIX A
}

\section{INFORMED CONSENT}

\author{
Illinois State University \\ Department of Psychology \\ Informed Consent for Participants \\ Principal Investigators: Ms. Alleana Fuentes and Dr. Jeffrey Kahn
}

Thank you for taking the time to participate in this research study, which is part of a Master's Thesis in the Department of Psychology. The policy of the Department of Psychology states that all research participation is voluntary, refusal does not result in penalty nor loss of benefits, and you have the right to discontinue from the study at any time, without penalty nor loss of benefits, should you object to the nature of the research. You are entitled to ask questions and to receive an explanation after your participation.

Purpose of the Research: This is a research study in which we will ask you to write about a personal stressor as well as your thoughts, feelings, and experience with it. We are interested in evaluating how these variables are related to one another among all study participants--we are not interested in information about any specific participant.

Nature of Your Participation: The research consists of thinking about a personal situation of yours, answering several questionnaires about emotions, and completing a 15-minute expressive writing task. The entire procedure is designed to be completed in approximately 45 minutes. You are free not to answer questions that make you uncomfortable and to not do the writing task if you choose.

Compensation: You will receive 1.5 points of extra credit to be used in your psychology course.

Benefits for Participating: You will also learn how writing about a personally difficult situation may improve your physical and mental health.

Risks and Privacy: First, you may find the task of writing about a personal experience and answering questions about it to be upsetting. For example, some survey questions ask about negative feelings or emotions. You do not have to answer any questions you feel uncomfortable answering. If you are feeling emotionally vulnerable, if you feel that your life stress is currently very hard to manage, or if you believe that describing a real-life stressor would be more than you want to handle at this time, then you should be aware that participation in this study might raise your risk of experiencing distress. Second, you will be asked to provide confidential information about yourself. All data will be kept secure, in accord with the standards of the University, Federal Regulations, and the American Psychological Association.

Mandated Reporting: We need to make you aware that in this research study, it is our legal and ethical responsibility to report situations of (a) child abuse, child neglect, or any life-threatening situation to a child as well as (b) illegal activity on the ISU campus, in campus-controlled locations, or involving ISU students to appropriate authorities. However, we are not seeking this type of information in our study, nor will you be asked questions about these issues. 
Questions or Concerns: If you have questions about this research project, you may contact the investigators (Ms. Alleana Fuentes at amfuent@ilstu.edu or Dr. Jeffrey Kahn at jhkahn@ilstu.edu). If you have questions about your rights as a research participant, you may contact the Research Ethics \& Compliance Office at (309) 438-2529.

Opportunities to Withdraw at Will: You may skip any questionnaire items or any part of this research you do not wish to do. If you decide now or at any point to withdraw this consent or stop participating, you are free to do so at no penalty to yourself.

Opportunities to be Informed of Results: In all likelihood, the results will be available after May 2017. If you wish to be told the results of this research, please contact Ms. Alleana Fuentes at amfuent@ilstu.edu. In addition, there is a chance that the results from this study will be published in a scientific psychology journal, which would be available in many libraries. In such an article, participants would be identified in general terms, as students at a large state university.

I agree to participate in this research:

Signature of Participant

Date 


\section{APPENDIX B}

\section{DEBRIEFING}

The purpose of the tasks you completed was to see if writing using a first person or third person perspective will create differences in the way one views their stressful situation. Our research was also focused on studying how these differences in perspective might influence a person's emotions and understanding about their stressor. The first questionnaires you answered looked into the ways you may typically experience and express emotions, the different emotions and behaviors you have, and information about your stressor. The writing task is used to measure the use of first person and third person pronouns. The last questionnaires you answered looked into the emotions and insight you have after the writing task.

Research on this topic should be of interest to college students, who experience multiple stressors and pressures daily. This may also be of interest to clinical and counseling psychologists who are interested in treating people who are experiencing unpleasant emotions. Social and personality psychologists might also find these results useful given the study's focus on emotion. Your participation was critical to our completing this research, and we thank you for your participation.

Although we hope this was not the case, we understand that some participants might have experienced some distress as a result of participating in this study. If this has been the case, please consider making an appointment to meet with someone from Student Counseling Services by calling (309) 438-3655 or stopping by room 320 of the Student Services Building. You can also call PATH--a 24-hour crisis line--at (888) 865-9903.

Also, if you have any questions related to this research or experienced any problems with the study you can talk with Dr. Jeffrey Kahn (jhkahn@ilstu.edu, 309-438-7939), the Principal Investigator of the study. If you have questions about your rights as a research participant, you may contact the Research Ethics \& Compliance Office at (309) 438-2529.

In this study, it is critical that future participants do not know anything about the study until after they have participated in it. This is necessary in order to prevent people from responding in a biased manner. Therefore, it is extremely important that you keep information about your experience today from other potential participants. We hope that you will respect the integrity of this research study by keeping the details of this study from others who may participate.

Thinking about a stressful situation can be difficult, and may lead one to feeling upset. Writing exercises can help one feel better, because they provide an opportunity to reflect on one's stressor in a private manner. Research has shown that writing about emotional topics can improve an individual's well-being. If you would like to learn more about such writing experiences, please visit this website:

https://pennebaker.socialpsychology.org/publications 